IZA DP No. 8444

Desert and Inequity Aversion in Teams

David Gill

Rebecca Stone

August 2014

Forschungsinstitut zur Zukunft der Arbeit Institute for the Study of Labor 


\title{
Desert and Inequity Aversion in Teams
}

\author{
David Gill \\ University of Oxford \\ and IZA \\ Rebecca Stone \\ UCLA
}

\section{Discussion Paper No. 8444 \\ August 2014}

IZA
P.O. Box 7240
53072 Bonn
Germany

\author{
Phone: +49-228-3894-0 \\ Fax: +49-228-3894-180 \\ E-mail: iza@iza.org
}

\begin{abstract}
Any opinions expressed here are those of the author(s) and not those of IZA. Research published in this series may include views on policy, but the institute itself takes no institutional policy positions. The IZA research network is committed to the IZA Guiding Principles of Research Integrity.

The Institute for the Study of Labor (IZA) in Bonn is a local and virtual international research center and a place of communication between science, politics and business. IZA is an independent nonprofit organization supported by Deutsche Post Foundation. The center is associated with the University of Bonn and offers a stimulating research environment through its international network, workshops and conferences, data service, project support, research visits and doctoral program. IZA engages in (i) original and internationally competitive research in all fields of labor economics, (ii) development of policy concepts, and (iii) dissemination of research results and concepts to the interested public.
\end{abstract}

IZA Discussion Papers often represent preliminary work and are circulated to encourage discussion. Citation of such a paper should account for its provisional character. A revised version may be available directly from the author. 
IZA Discussion Paper No. 8444

August 2014

\section{ABSTRACT}

\section{Desert and Inequity Aversion in Teams*}

Teams are becoming increasingly important in work settings. We develop a framework to study the strategic implications of a meritocratic notion of desert under which team members care about receiving what they feel they deserve. Team members find it painful to receive less than their perceived entitlement, while receiving more may induce pleasure or pain depending on whether their preferences exhibit desert elation or desert guilt. Our notion of desert generalizes distributional concern models to situations in which effort choices affect the distribution perceived to be fair; in particular, desert nests inequity aversion over money net of effort costs as a special case. When identical teammates share team output equally, desert guilt generates a continuum of symmetric equilibria. Equilibrium effort can lie above or below the level in the absence of desert, so desert guilt generates behavior consistent with both positive and negative reciprocity and may underpin social norms of cooperation.

JEL Classification: D63, J33

Keywords: desert, deservingness, equity, inequity aversion, loss aversion, reference-dependent preferences, guilt, reciprocity, social norms, team production

Corresponding author:

David Gill

Department of Economics

Manor Road Building

University of Oxford

Oxford OX1 3UQ

United Kingdom

E-mail: david.gill@economics.ox.ac.uk 


\section{Introduction}

Teams have become increasingly important in work settings in recent years (Che and Yoo, 2001, document a number of examples). The growing popularity of teams is driven partly by the increasing complexity of work tasks in a knowledge-driven environment. This increasing complexity means that tasks require the input of many different complementary skills and makes monitoring and legally verifying the value of individual contributions more difficult, thus leading to a greater use of teams with some form of output sharing.

Equity considerations are likely to play an important role when agents work together in teams. Team members will often be able to observe the performance of other team members, and team incentive schemes make team members' payoffs interdependent. Accordingly, if individual contributions to the team output vary across team members, rewarding team members with an equal share of the team output may "cause feelings of intraorganizational inequity: better performers are likely to feel inequitably treated when they are rewarded at the same level as poor performers in the same organization" (Lawler and Jenkins, 1992). Conversely, worse performers may feel that they have received more than they deserve. ${ }^{1}$

In this paper we develop a theoretical framework to study the strategic implications of desert considerations when agents work in teams. The increasing preponderance of teamwork makes understanding the incentives of team members more relevant than ever. A better understanding of incentives within teams that incorporates the implications of agents' desert concerns will provide a more solid foundation for future research to answer broader questions, such as: when will agents choose to join or form teams? when should employers use teams? how should employers design optimal team compensation? can employers help foster cooperation in teams by, e.g., providing information about the efforts of teammates or the efforts of others in similar teams? should profitsharing partnerships be taxed differently from other types of companies? ${ }^{2}$

Our analysis complements that of Gill and Stone (2010), who study the implications of desert in competitive settings in which payoffs are stochastic and reference points are expectations-based. Here we study implications of desert in a cooperative setting in which payoffs are deterministic.

1 In Section 2, we review the empirical evidence on the importance of equity considerations in team settings and more generally.

2 Our focus is on the impact of non-standard desert preferences on strategic behavior within teams under the simplest equal-sharing rule, which, as we document in footnote 4, is commonly used in teams. Holmstrom (1982) and Che and Yoo (2001) consider, in a static and dynamic context respectively, the choice of optimal team contract by a principal given standard preferences. In these papers, the principal is not constrained to use sharing rules that distribute output equally; indeed, the chosen contract does not even need to be budget balancing (i.e., payments are allowed to exceed output). We hope this paper will spur future research on how the multiplicity of equilibria that we find with desert preferences interacts with a principal's choice of optimal team contract. 
We develop a meritocratic notion of desert or equity under which each team member compares her monetary payoff to the payoff that she feels she deserves, which depends on how hard she has worked in relation to her teammates. When a team member receives less than she feels she deserves, she suffers a psychological cost which we call a desert loss. It is less clear whether she will view getting more than she deserves as a good thing or a bad thing, so we allow for both. We say that she benefits from desert elation if she feels good about getting more than she feels she deserves. When, instead, she feels bad about getting more than she feels she deserves, we say that she suffers from desert guilt. Such feelings of guilt may be triggered by a desire to conform with a meritocratic social norm according to which the distribution of payoffs should reflect recipients' efforts. ${ }^{3}$

Section 2 expounds our meritocratic notion of desert in more detail, relating it to the existing literature on equity and explaining how we formalize our notion using loss aversion around endogenous reference points. A significant body of empirical evidence from social psychology and experimental economics supports the idea that equity and desert are important when agents exert effort. However, the literature has not embedded desert in a formal framework suitable for studying its strategic implications.

Section 3 presents the formal model, which we apply in Section 4 to analyze the implications of desert for equilibrium effort choices in teams. When identical teammates share the team output equally, desert guilt generates a continuum of symmetric equilibria: some of these equilibria generate more effort than without desert; but, more surprisingly, other equilibria generate less effort than when desert considerations are absent. Desert guilt forges an endogenous complementarity between agents' efforts by giving the agents incentives to match the efforts of their teammates, and so generates behavior that is consistent with both positive and negative reciprocity. However, as outlined in Section 4.2, the mechanism that introduces reciprocity into our framework is different from that which drives intentions-based theories of reciprocal altruism. When desert guilt leads to cooperative behavior, the guilt can be thought of as underlying social norms of cooperation: desert guilt can make cooperation normatively appropriate for an agent, conditional on her teammates adhering to the norm of cooperative behavior. Thus desert guilt, which as noted above may itself be underpinned by a meritocratic social norm, can give rise to a specific norm of cooperation in our team setting. With desert elation, effort is always driven below the no-desert level as the team members feel no compunction about taking advantage of their teammates by slacking off. We also study the welfare implications of desert in Section 4.4.

3 As evidenced by Fershtman et al. (2012), whether people like or dislike coming out ahead of their peers depends on the norms induced by the specifics of the situation. 
The theoretical implications of desert in team settings in which an agent's effort confers a positive externality on her teammates are very different to those in settings in which agents compete and so impose negative externalities on rivals. As noted above, Gill and Stone (2010) consider the implications of desert in a competitive environment, finding that when agents compete desert concerns push identical agents to differentiate their effort levels, with some agents working very hard and others slacking off substantially. Eisenkopf and Teyssier (2013) provide support for this prediction using evidence from a laboratory experiment. The fact that desert concerns imply such different predictions across these different settings is evidence of the scope and portability of our notion of desert. Desert concerns may influence behavior in any situation in which agents exert effort, and an agent's payoff depends on her own effort as well as on the efforts of some other agents that she interacts with.

Our notion of desert can be seen as a generalization of distributional concern models to situations in which effort choices affect the distribution that is perceived to be fair or equitable. Desertconcerned agents care not just about the distribution of monetary payoffs, but also about how the distribution came about. Indeed, our conception of desert is related to the inequity-aversion model of Fehr and Schmidt (1999), and one of the aims of our paper is to clarify this relationship. In Section 5, we show that in a team setting our model of desert nests Fehr and Schmidt (1999)-type inequity aversion over monetary payoffs net of effort costs as a special case. Inequity aversion over money net of effort costs implies one particular way to weight monetary payoffs in relation to effort exerted, while our notion of desert does not prescribe the exact form that this weighting should take.

In Section 6 we study a simple linearized example that allows us to calculate explicit analytical expressions for the range of possible equilibria. We also use the linear example to study how desert concerns affect the optimal team size. We hope that this example will prove useful in future applied theoretical and empirical work. In Section 7, we consider the extent to which our results carry through when agents have heterogeneous desert preferences. Section 8 concludes. 


\section{Desert in teams}

In this section, we outline our general notion of desert in teams and link it to the existing literature.

We start by describing our team setting. A set of identical agents are members of a team: the agents exert costly effort to help produce some team output that is shared equally among the team members. ${ }^{4}$ Output sharing implies that each agent's effort confers a positive externality on her teammates. We also suppose that agents observe each other's contributions to the team output, while the contract setter cannot observe (or at least legally verify) individual efforts and so cannot condition payments directly on effort. This is a natural assumption when agents work together closely in a team, and it is commonly assumed in theoretical work on teams (see, e.g., Che and Yoo, 2001, and Kvaløy and Olsen, 2006). Finally, we abstract from one common feature of team production by assuming that the team production function does not exhibit complementarities in team members' efforts. We do this because our aim is to focus on the consequences of desert concerns for team production. In particular, we show that desert concerns create an endogenous complementarity: they give teammates an incentive to match one another's efforts in order to ensure that they receive their just deserts.

We capture a notion of desert or equity by supposing that each agent cares about how her monetary payoff compares to how much she feels she deserves, where this is given by a reference point $r_{i}$ that depends on how hard agent $i$ has worked in relation to her teammates. We also suppose that the agents share a common notion of desert and so agree about the payoff each deserves. Our general notion of desert is meritocratic: specifically, we assume that if an agent works harder than a teammate, she feels that she deserves more than that teammate, while if she works less hard she

4 Equal-sharing rules are common in team settings. Hamilton et al. (2003), for example, study the impact of a team incentive scheme in a garment factory under which teams received a group piece rate for each garment they produced as a team and the team's net receipts were divided equally among members. And Knez and Simester (2001) discuss a firm-wide bonus scheme used by the airline Continental, which promised 65 dollars to every hourly employee in every month that Continental's on-time performance ranked among the top five in the industry. More generally, partnerships often divide profits equally among partners. Encinosa et al. (2007), for example, analyze survey data on medical practices that was collected in 1978, finding that $54.2 \%$ of small medical-group practices (defined as practices of 3-5 physicians), which constituted $46 \%$ of all practices in their data, employed an equal-sharing rule (p.199). Unsurprisingly, a lower percentage of larger practices used an equal-sharing rule. But equal sharing was prevalent even in large practices: $6.9 \%$ of practices with 25 to 49 physicians and $31.4 \%$ of those with more than 50 physicians employed such a rule (p.199). Farrell and Scotchmer (1988) have data on law firms in 1980 that suggests that equal-sharing rules are common in law firms too. They report that most two or three-person law firms, which account for about two-thirds of all firms in their data, employed a system in which all members with the same seniority received the same profit share. As they explain, since "junior partners eventually become senior partners, such a system would be equal division if the firm's profitability were constant over time" (p. 293). Farrell and Scotchmer also report that salmon fishermen in the Pacific Northwest adhere to what amounts to an equal-sharing norm: they tell each other where the fish are while refraining from making side payments "thus sharing the efficiency gains from better information" (p. 279). 
feels that she deserves less. ${ }^{5}$ Letting $e_{i}$ represent agent $i$ 's effort:

$$
r_{i} \gtreqless r_{j} \Leftrightarrow e_{i} \gtreqless e_{j}
$$

We suppose that desert-motivated agents feel hard done by when they receive less than they feel they deserve, while feelings of elation or guilt are possible when they do better than they deserve. We operationalize our notion of desert by assuming that each agent is loss averse around her reference point, so losses relative to the deserved reference point are more painful than gains are pleasurable; indeed, doing better than is felt to be deserved may induce psychologically painful guilt rather than elation. Loss aversion captures the central stylized fact that has emerged from the empirical literature on reference-dependent preferences: losses relative to reference points loom larger than corresponding gains (see Rabin, 1998, and DellaVigna, 2009, for surveys, and the original paper by Kahneman and Tversky, 1979). In the terminology of Köszegi and Rabin (2007), the reference points in our setup are choice-acclimating and thus endogenous: the agents understand and anticipate how their effort choices influence their reference points. Gill and Stone (2010) consider a similar notion of desert, but in a competitive context where efforts impose a negative externality on rivals, and where there is uncertainty about agents' ultimate payoffs so that an agent's deserved reference point is given by her expected winnings. In a competitive tournament setting, Gill and Prowse (2012) find experimental evidence of the importance of loss aversion around choice-acclimating reference points. $^{6}$

Although little theoretical work has been carried out to model desert concerns formally, ${ }^{7}$ a

5 Our meritocratic notion of desert explicitly incorporates relative concerns: whether an agent feels that she deserves more or less than a teammate depends on whether she has worked more or less hard than that teammate. How hard an agent has worked could be measured in two ways: first, in terms of her individual investment or input, here measured by her 'cost of effort' (which gives the agent direct disutility); or second, in terms of her individual production or output that enters the team production function, here measured by her 'effort'. We have written our general notion of desert in terms of effort, but given our setting with identical agents we could equally well have written (1) in terms of cost of effort: an agent's effort exceeds that of a teammate if and only if her cost of effort also exceeds that of her teammate. If agents were not identical, but instead differed in their cost of effort functions, the distinction between individual investments and individual production would become relevant. In settings without a team production component, a 'libertarian' notion of distributive justice or fairness says that the fair distribution should depend on what each agent produces, while the 'liberal egalitarian' notion of distributive justice says that the fair distribution should depend on relative investments (see Cappelen et al., 2007). Applied to our team production setting, and if the agents differed in their cost of effort functions, the 'libertarian' notion would thus suggest that whether an agent deserves more than another should depend on relative efforts, while the 'liberal egalitarian' notion would suggest that desert should depend instead on relative costs of effort.

6 Daido and Murooka (2011) show that when workers are loss averse around choice-acclimating expectations, a principal might choose to use a 'team' contract under which one worker's pay increases in the performance of another in order to mitigate wage uncertainty.

7 An exception is Konow (2000), who considers only the optimal division of output by a dictator for given effort choices. Akerlof and Yellen (1990) invoke equity considerations to motivate an effort-supply function that is sensitive to the wage an agent receives relative to the wage she believes to be fair. 
significant body of literature supports the idea that people are motivated by a meritocratic notion of desert. Rabin (1998) writes that "desert will obviously be relevant in many situations - and the massive psychological literature on 'equity theory' shows that people feel that those who have put more effort into creating resources have more claim on those resources" (p. 18). Adams (1965) was the first modern proponent of equity theory: his work in social psychology led him to conclude that "when [a person] finds that his outcomes and inputs are not in balance in relation to those of others, feelings of inequity result" (p. 280) and that "there can be little doubt that inequity results in dissatisfaction, in an unpleasant emotional state, be it anger or guilt" (p. 283). Using survey data, Konow (1996) distills an accountability principle according to which a person's entitlement varies in direct proportion to the value of his relevant discretionary variables, relative to others (p. 19).

Experimental evidence also backs up the idea that people are sensitive to considerations of desert. For example, Konow (2000), Frohlich et al. (2004) and Cappelen et al. (2007) find evidence that in dictator games in which the amount to be distributed reflects agents' efforts, dictators tend to award a higher payoff to agents who have exerted more effort, while Abeler et al. (2010) show that when norms of equity are violated because harder working agents are paid the same as those who exert less effort, the harder working agents start to withdraw effort, even though it would be in their interest to continue to work hard in the absence of social preferences. Finally, in an experimental setting with different productivities, Gantner et al. (2001) classify subjects according to their equity standards.

The evidence referred to in the above two paragraphs that people care about equity considerations suggests that desert guilt is a more realistic assumption than desert elation in our team production context. When a team member receives more than she deserves, others receive less, and so if team members are genuinely motivated by the kind of fairness considerations that underlie equity theory, they should experience desert guilt when they receive more than they feel entitled to.

Further evidence that desert guilt is the more common motivational tendency among those who are sensitive to desert concerns comes from studies of team incentive schemes, which find that teams perform surprisingly well, at least under conditions in which team members can monitor each other's performance, contrary to the standard refrain that team incentives will lead to free-riding (see, e.g., Knez and Simester, 2001, Hamilton et al., 2003, and Boning et al., 2007). Experimental evidence also shows that there is less free-riding than standard theory predicts in team production 
games in which subjects contribute real effort (see, e.g., van Dijk et al., 2001, Mohnen et al., 2008, and Corgnet et al., 2011). Further evidence comes from Babcock et al. (2011), who conduct a field study in which team incentives (specifically a bonus that is paid only if both members of a team spend time studying or going to the gym a specified number of times) intensify the effort exerted by team members relative to an individual incentive scheme, a result they argue is attributable to the guilt team members experience when they let the team down. ${ }^{8}$ As we show in Section 4.4 below, when team members experience desert guilt the Pareto-dominant equilibrium involves more effort than if team members are self-interested or experience desert elation (which reduces effort below the self-interested level); if the agents succeed in coordinating on this equilibrium, then freeriding will be mitigated. The real-effort team production settings referenced above closely mimic our setup and so provide support for the existence of desert preferences with desert guilt and a reference point that depends on agents' relative contributions to the team.

Yet, even if desert guilt seems like the more plausible assumption, we think it makes sense to consider the possibility that agents experience desert elation for two reasons. First, the evidence suggests that there is heterogeneity in fairness preferences. For example, in a dictator game experiment by Frohlich et al. (2004) in which dictators are asked to divide an amount of money that is generated by the efforts of the dictator and a recipient, some dictators leave the recipient all that he deserves given their relative productivity, others leave none, while others leave an intermediary amount. Second, whether fairness perceptions matter to agents may depend on the specifics of the situation. While there is evidence that the basic tenets of equity theory are widely shared across different cultures (Konow, 2000), the salience of fairness considerations may vary depending on the social norms that govern the particular decision-making context. Contextual manipulations of the choice environment in dictator games can substantially alter behavior by altering subjects' sense of what is normatively appropriate (see, e.g., Krupka and Weber, 2013). And so it may be that a person's aversion to getting more than she deserves is context dependent.

8 Relatedly, Kuhn and Villeval (forthcoming) conduct a real-effort experiment in which they find that, in certain treatments, women are more attracted to team-based incentive schemes than men, a result that they argue may be attributed in part to greater aversion to advantageous inequity on the part of women than men. 


\section{Formal model}

We now imbed our notion of desert that we described above in Section 2 into a formal model.

\subsection{Team production game}

$N \geq 2$ identical agents simultaneously choose effort $e_{i} \geq 0$ at $\operatorname{cost} C\left(e_{i}\right)$, with $C(0)=C^{\prime}(0)=0$, $C^{\prime}>0$ for $e_{i}>0, C^{\prime \prime}>0$ and $C^{\prime}$ unbounded above. Team output $Y$ depends on the sum of the agents' efforts, so $Y=f\left(\sum_{i=1}^{N} e_{i}\right)$, with $f(0)=0, f^{\prime}>0$ and $f^{\prime \prime} \leq 0$. The team output is distributed equally, so each agent receives a monetary payoff $y_{i}=Y / N$, which the agent values at $\phi\left(y_{i}\right)$ with $\phi(0)=0, \phi^{\prime}>0$ and $\phi^{\prime \prime} \leq 0 .{ }^{9}$ The agents can produce output as part of the team but not individually (perhaps because access to a crucial means of production is tied to the team).

In the absence of desert preferences, to be introduced shortly, each agent has a twice continuously differentiable utility function $\bar{U}_{i}\left(e_{i}, e_{-i}\right)=\phi\left(y_{i}\right)-C\left(e_{i}\right)$, which depends on the agent's own effort $e_{i}$ and the vector of efforts chosen by the other team members $e_{-i} \cdot{ }^{10}$ We call $\bar{U}_{i}$ agent $i$ 's standard utility.

\subsection{Desert preferences}

As explained in Section 2, we capture agents' desert concerns by supposing that each agent cares not only about her monetary payoff and effort cost, but also about how the monetary payoff $y_{i}$ compares to a reference point $r_{i}$ that represents the payoff that the agent feels she deserves. We suppose that each agent's endogenous reference point is given by $r_{i}\left(e_{i}, e_{-i}\right)$, which is continuously differentiable when $\sum_{i=1}^{N} e_{i}>0$ and, letting $r_{i}^{\prime} \equiv \partial r_{i} / \partial e_{i}$ and $z_{-i}$ represent a common level of effort $e_{j}=z \forall j \neq i$, satisfies the following assumption:

Assumption 1 If $e_{j}=z>0 \quad \forall j \neq i$ then (i) $e_{i} \gtreqless z \Rightarrow r_{i}\left(e_{i}, z_{-i}\right) \gtreqless \frac{\left.f\left(e_{i}+(N-1) z\right)\right)}{N}$ and (ii) $r_{i}^{\prime}\left(z, z_{-i}\right)>\frac{f^{\prime}(N z)}{N}$.

Part (i) says that the identical agents adopt a meritocratic notion of desert such that if all agents exert a common level of effort $z$, each agent feels she deserves an equal $N^{\text {th }}$ share of the resulting team output, while if agent $i$ exerts more (less) effort than the common level of the other team members, she feels she deserves more (less) than the equal $N^{\text {th }}$ share $y_{i}$ that she receives.

9 It is straightforward to extend our analysis to the case where each individual's output is partially or fully non-rival in consumption. Each team member then receives $y_{i}=\frac{a Y}{N}=\frac{a f}{N}$, where $a$ ranges from 1 to $N$ as we move from full rivalry to full non-rivalry, so we can simply replace $f$ by af throughout.

${ }^{10}$ Although agents are identical and so share the same utility function, we find it useful to subscript utility and some other functions with an $i$ to denote the particular agent's identity. 
Part (i) follows from our general notion of desert (1), if we assume that $\sum_{i=1}^{N} r_{i}=Y$, so that the amounts felt to be deserved sum to the team output available for distribution. Part (ii) says that, starting from a common effort level $z$, the payoff that agent $i$ feels she deserves increases faster in her own effort $e_{i}$ than does her actual payoff, which is equivalent to saying that the share of team output felt to be deserved is strictly increasing. ${ }^{11}$ Part (ii) follows from part (i) in non-pathological cases. $^{12}$

Each agent's utility $U_{i}$ is assumed to take the following separable form:

$$
U_{i}\left(e_{i}, e_{-i}\right)=\phi\left(y_{i}\right)+D\left(\phi\left(y_{i}\right)-\phi\left(r_{i}\right)\right)-C\left(e_{i}\right)=\bar{U}_{i}\left(e_{i}, e_{-i}\right)+D\left(\phi\left(y_{i}\right)-\phi\left(r_{i}\right)\right)
$$

where desert utility $D\left(\phi\left(y_{i}\right)-\phi\left(r_{i}\right)\right)$ represents the reference-dependent utility that the agent experiences from comparing her monetary payoff to her reference point. Desert utility depends on $\triangle_{i} \equiv \phi\left(y_{i}\right)-\phi\left(r_{i}\right)$, that is, on the difference between the material utility derived from the agent's share of output and the material utility associated with receiving the deserved reference point. It is important to emphasize that in this formulation an agent's reference point is choice-acclimating and hence endogenous: as the agent changes her effort choice, her reference point adjusts, and the agent anticipates this when deciding how hard to work.

We let desert utility $D\left(\triangle_{i}\right)$ be a continuous function with $D\left(\triangle_{i}\right)=L\left(\triangle_{i}\right)$ when $\triangle_{i}<0$, $D\left(\triangle_{i}\right)=0$ when $\triangle_{i}=0$ and $D\left(\triangle_{i}\right)=G\left(\triangle_{i}\right)$ when $\triangle_{i}>0$. Since $\phi^{\prime}>0, \triangle_{i} \gtreqless 0 \Leftrightarrow \phi\left(y_{i}\right) \gtreqless$ $\phi\left(r_{i}\right) \Leftrightarrow y_{i} \gtreqless r_{i}$. Thus, $L\left(\triangle_{i}\right)$ represents the desert utility associated with situations in which $y_{i}<r_{i}$, so the agent receives less than she feels she deserves. In such cases, we say that the agent suffers a desert loss, and we assume that $L\left(\triangle_{i}\right)<0$ for all $\triangle_{i}<0$, so such losses are always unambiguously painful. $G\left(\triangle_{i}\right)$ represents the desert utility when $y_{i}>r_{i}$, so the agent receives more than she feels she deserves. When $G\left(\triangle_{i}\right)>0$, we say the agent derives desert elation from $\triangle_{i}>0$ : she gains pleasure from doing better than deserved. When $G\left(\triangle_{i}\right)<0$ we say the agent suffers desert guilt from $\triangle_{i}>0$ : doing better than is felt to be deserved induces a psychological

${ }^{11}$ The share felt to be deserved is given by $\frac{r_{i}}{f}$ and the derivative of this share with respect to $e_{i}$ is given by $\frac{r_{i}^{\prime} f-r_{i} f^{\prime}}{f^{2}}$. At a common effort level $z>0, \frac{r_{i}}{f}=\frac{1}{N}$, so this derivative is strictly positive if and only if (ii) holds.

${ }^{12}$ Part (i) implies that $r_{i}\left(e_{i}, z_{-i}\right)$ crosses $\frac{f\left(e_{i}+(N-1) z\right)}{N}$ from below at $e_{i}=z$, so $r_{i}^{\prime}\left(z, z_{-i}\right) \geq \frac{f^{\prime}(N z)}{N}$, with strict inequality in non-pathological cases. 
cost which we call guilt. ${ }^{13}$ Letting $G^{\prime}(0) \equiv \lim _{\triangle_{i} \downarrow 0} G^{\prime}\left(\triangle_{i}\right)$, we define local and global desert guilt and elation as follows:

Definition 1 The agents exhibit local desert guilt if $G^{\prime}(0)<0$. They exhibit global desert guilt if $G^{\prime}(0)<0$ and $G\left(\triangle_{i}\right)<0$ for all $\triangle_{i}>0$.

Definition 2 The agents exhibit local desert elation if $G^{\prime}(0)>0$. They exhibit global desert elation if $G^{\prime}(0)>0$ and $G\left(\triangle_{i}\right)>0$ for all $\triangle_{i}>0$.

As discussed in Section 2, we assume that each agent is loss averse around her choice-acclimating endogenous reference point. In particular, letting $L^{\prime}(0) \equiv \lim _{\triangle_{i} \uparrow 0} L^{\prime}\left(\triangle_{i}\right)$, we assume that desert utility $D\left(\triangle_{i}\right)$ is differentiable everywhere away from $\triangle_{i}=0$, that $L^{\prime}(0)>0$, and that $L^{\prime}(0)>G^{\prime}(0)$. Thus, in the limit as the deviation from the reference point tends to zero, desert losses remain painful and desert losses are more painful than any desert elation is pleasurable: the agents are loss averse for small stakes. This corresponds to Assumption A4 in Kőszegi and Rabin's (2006) formal description of loss aversion, and implies a kink in utility at the reference point. ${ }^{14}$ Models of loss aversion generally also assume loss aversion for large stakes, weak convexity in the loss domain and weak concavity in the gain domain (Assumptions A2 and A3 in Köszegi and Rabin, 2006), but our results do not require such assumptions.

\subsection{Examples}

To fix ideas, we now provide a few concrete examples of desert preferences which satisfy the assumptions outlined above. We start by presenting three plausible forms for the reference point. All three satisfy Assumption 1 and our general notion of desert (1). First, an agent could feel that she deserves a share of team output equal to her share of effort, so:

$$
r_{i}=\frac{e_{i}}{\sum_{i=1}^{N} e_{i}} f\left(\sum_{i=1}^{N} e_{i}\right) \quad \text { when } \sum_{i=1}^{N} e_{i}>0
$$

${ }^{13}$ We take the classical view of guilt as arising from "private feelings associated with a troubled conscience" (Smith et al., 2002, p. 138). However, nothing in the structure of our model precludes a role for other negative emotions linked to publicity such as shame which involves "an unpleasant emotional reaction by an individual to an actual or presumed negative judgment of himself by others" (Ausubel, 1955, p. 382). Note also that desert guilt differs from the guilt aversion of Battigalli and Dufwenberg (2007), who use dynamic psychological game theory to model guilt from reducing another agent's payoff below her expectations. In our model, an agent can feel guilt even when others' expectations are confirmed.

${ }^{14}$ Note that in Köszegi and Rabin's (2006) formalization, $L^{\prime}(0)>G^{\prime}(0)>0$, so that in the limit receiving less than the reference point is always painful but receiving more is always pleasurable. In our desert framework, we allow $G^{\prime}(0)<0$ to capture desert guilt. 
This reference point function is an example of the 'classic proportionality' fairness principle. According to Almås et al. (2011, p. 490): "The classical proportionality principle is a well-known responsibility-sensitive fairness principle, where income is distributed in proportion to each individual's claim and where the claim is given by the value of the factor for which the individual is responsible. For example, if we assume that the number of working hours is the only responsibility factor, then a person's claim is equal to the number of hours worked. In this case, the classical proportionality principle assigns to each individual a share of the total income that is equal to his share of the total number of hours worked." In (3) an individual's 'effort', which measures the individual's production or output that enters the team production function, is taken to be the relevant responsibility factor.

Second, the agent might feel that she deserves a share of team output equal to her share of the cost of effort, so:

$$
r_{i}=\frac{C\left(e_{i}\right)}{\sum_{i=1}^{N} C\left(e_{i}\right)} f\left(\sum_{i=1}^{N} e_{i}\right) \quad \text { when } \sum_{i=1}^{N} e_{i}>0 \text { so } \sum_{i=1}^{N} C\left(e_{i}\right)>0 .
$$

This reference point function is another example of classic proportionality, where now an individual's 'cost of effort', which measures the individual's investment or input that gives her direct disutility, is taken to be the relevant responsibility factor.

Finally, the agent could feel that she deserves an equal share of the team output that would have been produced had everybody worked as hard as she did, so:

$$
r_{i}=\frac{f\left(N e_{i}\right)}{N}
$$

This reference point function is related to the 'egalitarian equivalent' fairness principle, which is an alternative responsibility-sensitive fairness principle to the classic proportionality principle (Bossert and Fleurbaey, 1996). Almås et al. (2011) present two different versions. According to the version represented by equation (9) at p.497, the fair distribution to agent $i$ is given by what the average level of pre-tax income in the economy would have been had everybody's vector of responsibility factors matched that of agent $i$ (together with a uniform transfer designed to ensure that the total of the fair distributions matches actual production). The setting in Almås et al. (2011) is not directly applicable to our team production setting, since pre-tax income is allowed to vary only in individuals' own vector of characteristics. However, Bossert (1995, p.3) notes that "A possible generalization... would be to allow pre-tax incomes to depend on the entire characteristics profile." 
Given such a generalization, and when effort is taken to be the responsibility factor, this version of the egalitarian equivalent principle gives our reference point (5), except for the uniform transfer (which is zero in the case of our linear example in Section 6). ${ }^{15}$

Next, we present one simple piecewise-linear form for desert utility $D\left(\triangle_{i}\right)$ which satisfies our assumptions on desert utility outlined above. We present this example for illustrative purposespiecewise linearity is not required for our equilibrium results in Section 4. With piecewise linearity, $D\left(\triangle_{i}\right)=L\left(\triangle_{i}\right)=l \triangle_{i}$ when $\triangle_{i}<0, D\left(\triangle_{i}\right)=0$ when $\triangle_{i}=0$ and $D\left(\triangle_{i}\right)=G\left(\triangle_{i}\right)=g \triangle_{i}$ when $\triangle_{i}>0$; thus $l$ represents the slope of desert utility when the agent receives less than she feels she deserves and $g$ represents the slope when the agent receives more. To ensure that an agent suffers a desert loss when she receives less than she feels she deserves, i.e., $L\left(\triangle_{i}\right)<0$, we assume that $l>0$. Desert guilt (Definition 1) implies that $g<0$ while desert elation (Definition 2) implies that $g>0$. Note that with piecewise linearity there is no longer a distinction between local and global desert guilt or between local and global desert elation, and our assumption of loss aversion boils down to assuming that $l>g$. Applications of loss aversion often use a piecewise-linear functional form (for some recent examples see Crawford and Meng, 2011, and Gill and Prowse, 2012); in particular, Gill and Stone's (2010) analysis of desert in competitive environments assumes piecewise linearity throughout.

\subsection{Desert equilibrium}

Taking the efforts of her teammates $e_{-i}$ as given, each agent chooses her own effort $e_{i}$ to maximize her utility $U_{i}$. Having exerted her chosen effort, each agent receives her monetary payoff and also observes the effort levels of her teammates. Observability implies that the agents do not have to try to infer other agents' efforts from the team output. When an agent's reference point $r_{i}$ depends only on her own effort $e_{i}$ and the sum of her teammates' efforts $\sum_{j \neq i} e_{j}$, as will be the case in the linear example of Section 6, the assumption of observability is superfluous as $\sum_{j \neq i} e_{j}$ can be inferred perfectly from the agent's monetary payoff $y_{i}$. We restrict attention to pure-strategy Nash

\footnotetext{
${ }^{15}$ Almås et al. (2011) also present the 'conditional egalitarian' principle and an alternative form of the egalitarian equivalent principle. These are designed to account for differences in non-responsibility factors. In our setting with identical agents, the agents share the same vector of non-responsibility factors, and so these principles have no bite.
} 
equilibria, which we call desert equilibria. ${ }^{16}$

\section{Equilibrium analysis}

\subsection{No desert}

As a benchmark, we first solve for equilibrium play when the agents do not have desert preferences. The equilibrium is symmetric and interior. Defining social welfare as the sum of utilities, so welfare $W \equiv \sum_{i=1}^{N} U_{i}$, effort in the unique equilibrium is socially too low due to the positive externality inherent in the team production game.

Proposition 1 In the absence of desert, there is a unique and symmetric pure-strategy Nash equilibrium in which the agents exert strictly positive effort $\widetilde{e}$. Equilibrium effort is strictly lower than the socially optimal effort level $e^{w}$.

Proof. See Appendix.

\subsection{Desert guilt}

When agents suffer from global desert guilt (see Definition 1), so that they always dislike receiving more than they feel they deserve, desert generates a range of symmetric equilibria around the no-desert equilibrium $\widetilde{e}$ as Proposition 2 illustrates. ${ }^{17}$

Proposition 2 When the agents exhibit global desert guilt, a range of symmetric desert equilibria exists around the equilibrium level of effort in the absence of desert $\widetilde{e}$, with some equilibria strictly above and some strictly below $\widetilde{e}$.

16 Technically, our game is psychological (Geanakoplos et al., 1989) as agent $i^{\prime} s$ utility depends on her belief about the efforts of her teammates via the reference point. In particular, our game falls under Battigalli and Dufwenberg's (2009) framework of a dynamic psychological game as utility depends on terminal node (ex post) beliefs, so beliefs can update during the course of the game (in contrast to Geanakoplos et al., in which utilities only depend on initial beliefs). However, we have assumed that the agents observe each other's efforts ex post, so the actual efforts pin down these beliefs at the terminal nodes. Thus we do not need to introduce the apparatus of psychological games: we can write payoffs as a function of actions alone, given the actions determine the first-order beliefs. Even in the absence of observability, the set of pure-strategy equilibria would remain the same: the discussion in the third-from-last paragraph of Section 2 in Gill and Stone (2010) also applies here.

${ }^{17}$ When the agents exhibit neither desert guilt nor desert elation, the proof of Proposition 2 extends naturally to show that there is a range of symmetric equilibria with all equilibria weakly below $\widetilde{e}$. When the agents exhibit neither desert guilt nor desert elation, $D\left(\triangle_{i}\right)=0$ when $\triangle_{i} \geq 0$ because the agents are indifferent to receiving as much as or more than they feel they deserve, but $D\left(\triangle_{i}\right)<0$ when $\triangle_{i}<0$ because the agents continue to suffer desert losses when they receive less than they feel they deserve. For a common effort level $z \leq \widetilde{e}$, the proof of Proposition 2 continues to show that upward deviations are not profitable when $z$ is close enough to or equal to $\widetilde{e}$. From part (a) of the proof, all downward deviations reduce standard utility when $z \leq \widetilde{e}$, and from part (b), local downward deviations increase standard utility when $z>\widetilde{e}$. Thus, there exists a profitable downward deviation if and only if $z>\widetilde{e}$, given that downward deviations do not change desert utility since they give $\triangle_{i}>0$ and hence $D=0$. 


\section{Proof. See Appendix.}

The intuition is as follows. If an agent increases her work effort above the common effort level of her teammates, she raises the reference point that she feels she deserves above the equal share of the team output that she receives. Thus she suffers a desert loss as she receives less than she feels she deserves. If, instead, the agent reduces her work effort below that of her teammates, she suffers from desert guilt as her deserved reference point falls below an equal share of team output, and so she receives more than she feels she deserves. Thus, starting from a common effort level, desert considerations reduce both the incentive to increase and to decrease effort. When the common effort level is not too far from the no-desert equilibrium, these desert considerations dominate, thus generating a symmetric equilibrium. Essentially, desert forges an endogenous complementarity between agents' efforts by giving them incentives to match the efforts of their teammates in equilibrium.

Proposition 2 tells us that, perhaps unsurprisingly, desert guilt can make the agents work harder in equilibrium. ${ }^{18}$ Thus desert guilt, which as noted in the Introduction may itself be underpinned by a desire to conform to a meritocratic social norm, can give rise to a specific social norm of cooperation in our team production setting: desert guilt can make cooperation normatively appropriate for an agent, conditional on her teammates adhering to the norm of cooperative behavior. Once a norm of cooperation starts to become established, desert guilt can help to ensure that the agents stick to the norm without the need for any external pressure or sanctions. In practice, however, we might expect desert guilt to interact with external enforcement mechanisms such as public shame and punishment in forming and underpinning social norms of cooperation. ${ }^{19}$ The importance of social norms suggests that employers using teams might try to mold perceptions of norms by, for instance, providing team members with information about effort levels in other similar, successful teams.

More unexpectedly, with desert guilt there is a whole range of possible symmetric equilibria, some of which involve less effort than in the absence of desert considerations. Our theory of desert thus endogenously generates behavior that is consistent with both positive and negative reciprocity, since agents match the level of cooperation of their teammates.

${ }^{18}$ Kandel and Lazear (1992) and Mohnen et al. (2008) study the effect of peer pressure on effort in a team production setting. Kandel and Lazear assume that peer pressure operates linearly, and so raises effort in the unique symmetric equilibrium. Mohnen et al. assume that the peer pressure function is convex, and so has no effect on equilibrium effort in a single-stage game. Corgnet et al. (2011, 2013) show experimentally that peer monitoring increases peer pressure in teams.

${ }^{19}$ See Young (1998), Bicchieri (2006) and Krupka and Weber (2009) for further discussion and experimental evidence of the role of social norms and the importance of context and expectations in how norms drive behavior. 
A number of experiments provide evidence that a large proportion of subjects in contribution games exhibit conditionally cooperative behavior. In linear public good games, Fischbacher et al. (2001), Croson (2007), and Fischbacher and Gächter (2010) elicit contribution schedules, finding that a majority of subjects show a positive relationship between desired contribution levels and the group average, while Falk et al. (2013) find that the same individual contributes more to a public good when he is a member of a group with higher average contributions. In these types of linear public good experiments, contributions are monetary and tend to fall over time towards the selfish Nash equilibrium. However, with real effort in a team production setting van Dijk et al. (2001) find no free-riding on average, with no tendency for the average amount of free-riding to increase over time. We would expect deservingness to be more salient when subjects exert real effort; thus in an environment with real effort desert-type considerations should be better able to sustain cooperative behavior over time. In non-linear public good experiments (with interior selfish Nash equilibria) average contributions sometimes fall below the selfish Nash equilibrium level, suggesting negative reciprocity (see Isaac and Walker, 1998, Cason et al., 2002, 2004, and the survey by Laury and Holt, 2008).

We stress, however, that the mechanism which introduces reciprocity into our framework is different to that which drives intentions-based theories of reciprocal altruism. Intentions-based models explain conditional cooperation by assuming that agents like to reciprocate kindness by helping those who are kind to them but hurting those who are mean to them (see for instance Rabin, 1993, Dufwenberg and Kirchsteiger, 2004, and Falk and Fischbacher, 2006). The perceived kindness of an action is determined by the perceived intention of the agent, which introduces hierarchies of beliefs into utility. In contrast, our theory of desert predicts reciprocal behavior without the need to introduce beliefs about motives or intentions of other agents. ${ }^{20}$

\subsection{Desert elation}

When agents exhibit local desert elation (see Definition 2), so the agents actively like receiving slightly more than they feel they deserve, Proposition 3 shows that effort in a symmetric equilibrium must decline compared to the case where the agents do not have desert preferences.

\footnotetext{
${ }^{20}$ Some authors impose reciprocity by simply assuming that certain actions induce a reciprocal response without any consideration of intentions, which of course can give rise to multiple equilibria. In various team production-type settings Sugden (1984), Rob and Zemsky (2002) and Huck et al. (2012) impose positive reciprocity, Sugden by assuming that at a minimum agents want to match the lowest of their rivals' efforts, Rob and Zemsky by assuming that the greater the degree of cooperation in the previous period, the more employees want to cooperate now, and Huck et al. by assuming that the strength of a preference for conforming to a social norm is increasing in the degree of conformity of the other players.
} 
Proposition 3 When agents exhibit local desert elation, effort in any symmetric desert equilibrium is strictly lower than the equilibrium level of effort in the absence of desert $\widetilde{e}$.

Proof. See Appendix.

Local desert elation implies that, starting from a common level of effort, the local incentive to reduce effort is now higher than in the absence of desert considerations. Agents like receiving more than they feel they deserve, and by reducing effort an agent lowers her deserved reference point below the equal share of team output that she receives. Thus no common effort level at or above the no-desert equilibrium $\widetilde{e}$ can form a symmetric equilibrium, as the agents would want to slack off to enjoy some desert elation. The linear example in Section 6 illustrates that a range of symmetric equilibria may exist below $\widetilde{e}$. In this range, the common effort level is low enough that the desert elation from deviating to an even lower level of effort is outweighed by the reduction in standard utility $\bar{U}_{i}$.

We can also show that a range of symmetric equilibria must exist when the weight on desert elation becomes sufficiently small. To formalize this, we introduce explicit weights on desert utility relative to standard utility, as follows:

$$
\begin{aligned}
\mathcal{L}\left(\triangle_{i}, \lambda_{l}\right) & =\lambda_{l} L\left(\triangle_{i}\right) \\
\mathcal{G}\left(\triangle_{i}, \lambda_{g}\right) & =\lambda_{g} G\left(\triangle_{i}\right) \\
\lambda_{l} & \geq \lambda_{g}>0 \\
U_{i} & =\bar{U}_{i}+\mathcal{L}\left(\triangle_{i}, \lambda_{l}\right) \mathbf{1}_{\triangle_{i}<0}+\mathcal{G}\left(\triangle_{i}, \lambda_{g}\right) \mathbf{1}_{\triangle_{i}>0} .
\end{aligned}
$$

Thus, $\lambda_{l}$ represents the weight on desert losses and $\lambda_{g}$ the weight on desert elation or guilt. We continue to make the same assumptions on $L\left(\triangle_{i}\right)$ and $G\left(\triangle_{i}\right)$ as before. The assumption that $\lambda_{g}>0$ ensures that $\mathcal{G}\left(\triangle_{i}, \lambda_{g}\right)$ exhibits local desert elation or guilt if and only if $G\left(\triangle_{i}\right)$ does, since $\mathcal{G}^{\prime}\left(0, \lambda_{g}\right)=\lambda_{g} G^{\prime}(0)$. It also ensures that $\mathcal{G}\left(\triangle_{i}, \lambda_{g}\right)$ exhibits global desert elation or guilt if and only if $G\left(\triangle_{i}\right)$ does. The assumption that $\lambda_{l}>0$ ensures that $\mathcal{L}\left(\triangle_{i}, \lambda_{l}\right)<0$ when $\triangle_{i}<0$, given $L\left(\triangle_{i}\right)<0$; that is, desert losses continue to be painful. The assumption that $\lambda_{l} \geq \lambda_{g}$ ensures that $\mathcal{L}^{\prime}\left(0, \lambda_{g}\right)>\mathcal{G}^{\prime}\left(0, \lambda_{g}\right)$, given $L^{\prime}(0)>G^{\prime}(0)$; that is, we continue to have loss aversion for small stakes.

For given $\lambda_{l}$ and $\lambda_{g}$, the new desert utility function $\mathcal{D}\left(\triangle_{i}, \lambda_{l}, \lambda_{g}\right)=\mathcal{L}\left(\triangle_{i}, \lambda_{l}\right) \mathbf{1}_{\triangle_{i}<0}+\mathcal{G}\left(\triangle_{i}, \lambda_{g}\right) \mathbf{1}_{\triangle_{i}>0}$ retains all properties of the old desert utility function $D\left(\triangle_{i}\right)=L\left(\triangle_{i}\right) \mathbf{1}_{\triangle_{i}<0}+G\left(\triangle_{i}\right) \mathbf{1}_{\triangle_{i}>0}$. Thus, Propositions 2 and 3 continue to hold. However, we can now complement Proposition 3 by showing 
that with desert elation, not only can there be no symmetric equilibrium with effort at or above the equilibrium level in the absence of desert $\widetilde{e}$, there must also exist a range of equilibria below $\widetilde{e}$ when the weight on desert elation is small.

Proposition 4 When agents exhibit local desert elation, a range of symmetric desert equilibria exists if the weight $\lambda_{g}$ on the desert elation component of utility is sufficiently small, with all equilibria strictly below the equilibrium level of effort in the absence of desert $\widetilde{e}$.

Proof. See Appendix.

The intuition is as follows. When the common level of effort is close to but below the equilibrium level of effort in the absence of desert, agents have no incentive to deviate by working harder than their teammates, since the desert losses that they would suffer from receiving less than they feel they deserve would exceed the gain in standard utility. When the weight on desert elation is sufficiently small, they also have no incentive to deviate by working less hard than their teammates, since the desert elation that they would gain from receiving more than they feel they deserve would not exceed the loss in standard utility from the deviation.

\subsection{Efficiency with desert preferences}

In this section, we evaluate the welfare properties of the equilibria given the desert preferences exhibited by the agents. Remember that we defined social welfare as the sum of utilities, so $W=\sum_{i=1}^{N} U_{i}{ }^{21}$ Part (i) of the following proposition tells us that under desert guilt there is a unique welfare-maximizing level of effort (which is the same as the efficient level under standard preferences). Part (ii) tells us that it is always better for the agents to coordinate on a symmetric equilibrium closer to the welfare-maximizing level. Thus, fixing desert preferences, the greater the success of the agents in using desert concerns to overcome the free-rider problem in the team production game by coordinating on a higher-effort equilibrium, the higher is social welfare, so long as there is no desert equilibrium involving effort above the efficient level. If agents exhibit desert guilt, the latter condition may not hold, in which case desert guilt can push the agents to work too hard in equilibrium.

${ }^{21}$ If desert concerns capture an agent's moral judgment about what she ought to do rather than representing a component of her well-being, welfare should exclude desert utility. Of course this distinction has no effect on behavior, and since we focus on symmetric equilibria in which desert utility is zero in equilibrium, the distinction is not important for welfare in equilibrium. 


\section{Proposition 5}

(i) If the agents exhibit global desert guilt, there is a unique socially optimal level of effort $e^{w}$ (which is the same as in the absence of desert preferences).

(ii) Given desert guilt or desert elation, and assuming the agents play a symmetric desert equilibrium with strictly positive effort, welfare is concave in effort with a maximum at $e^{w}$. Thus, when there is a range of equilibria with an upper bound below $e^{w}$, welfare is increasing in the level of effort that the agents coordinate on.

Proof. See Appendix.

\subsection{The importance of loss aversion}

In this section, we consider explicitly which of our results depend on the assumption of loss aversion. Loss aversion (or more specifically, the assumption that desert utility is kinked at the reference point) is necessary to derive Proposition 2. Without it, desert concerns would not generate a range of symmetric equilibria with global desert guilt. At any common effort level $z, \triangle_{i} \equiv \phi\left(y_{i}\right)-\phi\left(r_{i}\right)=$ 0 and desert utility $D(0)=0$ since the agent receives what she feels she deserves. Desert losses are always painful, so $D\left(\triangle_{i}\right)=L\left(\triangle_{i}\right)<0$ for $\triangle_{i}<0$. Under global desert guilt, $D\left(\triangle_{i}\right)=G\left(\triangle_{i}\right)<0$ for $\triangle_{i}>0$. Thus, if there were no kink in desert utility at $\triangle_{i}=0$, it would have to be the case that $\partial D\left(\triangle_{i}\right) / \partial e_{i}=0$ when $\triangle_{i}=0$. Therefore, at any common effort level $z$ the derivative of desert utility would drop out of the first-order condition, and so by the proof of Proposition 1 there would be a unique $z$ satisfying the first-order condition, ruling out a range of symmetric equilibria. Proposition 3 would hold even if the agents were not loss averse. In the absence of a kink in desert utility, agents would still want to deviate downward from the equilibrium level of effort without desert in order to experience desert elation. Loss aversion is necessary for Proposition 4 to hold in general. For example, there would be a unique symmetric equilibrium in the linear example of Section 6 in the absence of a kink in desert utility. Finally, Proposition 5 would continue to hold in the absence of loss aversion. 


\section{$5 \quad$ Inequity aversion as a special case of desert}

Our notion of desert can be seen as a generalization of distributional concern models to situations in which effort choices affect the distribution that is perceived to be fair or equitable. Desertconcerned agents care not just about the distribution of monetary payoffs, but also about how the distribution came about. Indeed, our notion of desert is related to the inequity-aversion models of Fehr and Schmidt (1999) and Bolton and Ockenfels (2000), and one of the aims of this paper is to clarify this relationship in a team production setting. Inequity-averse agents, like desert-concerned agents, care about the distribution of resources in addition to their own material payoffs. Inequity aversion over monetary payoffs alone plays no role in our team production setting because all the agents receive the same equal share of the team output. Desert-concerned agents, by contrast, care about the relationship between the distribution of monetary payoffs and the distribution of agents' efforts, and not just about the brute distribution of money. However, agents might be inequity averse over monetary payoffs net of effort costs, in which case they too will be concerned with the relationship between money and effort. ${ }^{22}$

In fact, it turns out that Fehr and Schmidt (1999) inequity aversion over money net of effort costs is a special case of our more general notion of desert: we show below that inequity aversion over money net of effort costs corresponds to a particular form of the reference point that is felt to be deserved, while our theory of desert leaves open the form of the functional relationship between efforts and deservingness. Also, for analytical tractability Fehr and Schmidt (1999) impose piecewise-linear loss aversion, while our theory allows desert utility to take on arbitrary non-linear shapes around the kink implied by loss aversion.

If we apply Fehr and Schmidt's (1999) model of inequity aversion (equation (1) at p. 822) to our team production game, and assume aversion to differences in monetary payoffs net of effort costs, then:

$$
U_{i}\left(e_{i}, e_{-i}\right)=y_{i}-C\left(e_{i}\right)-\frac{\alpha}{N-1} \sum_{j \neq i} \max \left\{C\left(e_{i}\right)-C\left(e_{j}\right), 0\right\}-\frac{\beta}{N-1} \sum_{j \neq i} \max \left\{C\left(e_{j}\right)-C\left(e_{i}\right), 0\right\},
$$

22 A few papers analyze the consequences of inequity aversion over monetary payoffs net of effort costs. Demougin and Fluet (2003) evaluate the impact in tournaments, Kölle et al. (2011) study the impact on contributions to a public good (focusing on the role of initial wealth differences, they find that a continuum of equilibria may exist), and a burgeoning literature looks at the implications for contract design (Itoh, 2004, Demougin and Fluet, 2006, Demougin et al., 2006, Desiraju and Sappington, 2007, Rey Biel, 2008, Bartling and von Siemens, 2010, Bartling, 2011, von Siemens, 2011, 2012). 
where $\alpha \geq \beta, \alpha>0$ and $\beta \in[0,1) .{ }^{23}$ Note that monetary payoffs drop out of the comparison terms because $y_{i}=y_{j}=f\left(\sum_{i=1}^{N} e_{i}\right) / N$ for all $i, j$ pairs.

With just two agents, it is straightforward to see that (10) is a special case of our model of desert. The reference point that agent $i$ feels she deserves is then given by:

$$
r_{i}\left(e_{i}, e_{-i}\right)=\frac{f\left(\sum_{i=1}^{N} e_{i}\right)}{N}+C\left(e_{i}\right)-C\left(e_{j}\right),
$$

which satisfies Assumption 1 and our general notion of desert (1). Money utility is linear, so $\phi\left(y_{i}\right)=y_{i}$. Desert utility $D\left(\triangle_{i}\right)$ takes the piecewise-linear form outlined in the second paragraph of Section 3.3, with $l=\alpha, g=-\beta$ and $\triangle_{i}=y_{i}-r_{i}=C\left(e_{j}\right)-C\left(e_{i}\right)$. The assumption of loss aversion, i.e., that $l>g$, corresponds to $\alpha>-\beta$ which always holds in Fehr and Schmidt (1999) given $\alpha>0$ and $\beta \geq 0$. Thus we have the following result.

Proposition 6 When there are two agents, our model of desert nests inequity aversion over monetary payoffs net of effort costs as a special case.

When the aversion to advantageous inequity is strict, i.e., $\beta>0$, the agents exhibit global desert guilt (Definition 1) as $G^{\prime}(0)=-\beta<0$ and $G\left(\triangle_{i}\right)=-\beta \triangle_{i}<0$ for all $\triangle_{i}>0$. Thus Proposition 2 applies. Fehr and Schmidt (1999) do not allow agents to like advantageous inequity, i.e., they exclude the case where $\beta<0$. Nonetheless, we also consider this case. When $\beta<0$, the agents exhibit local desert elation (Definition 2) as $G^{\prime}(0)=-\beta>0$. Thus Proposition 3 applies, so long as we maintain the assumption of loss aversion so $\alpha>-\beta$.

When there are more than two agents, the Fehr and Schmidt (1999) model, outlined above in (10), involves a series of pairwise comparisons. To see the connection between inequity aversion over money net of effort costs and our model of desert, we therefore need to broaden our model of desert to also allow for pairwise desert comparisons.

Let $q\left(e_{i}, e_{j}, e_{-i j}\right)$ represent how much more or less agent $i$ feels that she deserves relative to agent $j$, where $e_{-i j}$ represents the vector of effort choices of all the other agents. In order to satisfy our general notion of desert (1), which says that agent $i$ feels she deserves more (less) than agent $j$ if and only if she works harder (less hard), we assume that:

$$
q\left(e_{i}, e_{j}, e_{-i j}\right) \gtreqless 0 \Leftrightarrow e_{i} \gtreqless e_{j} .
$$

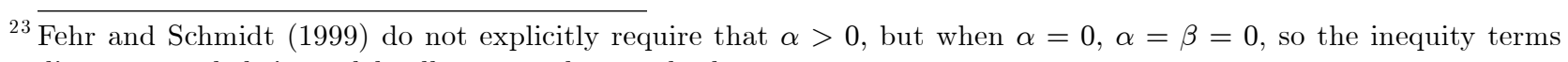
disappear and their model collapses to the standard one. 
Letting $\triangle_{i j} \equiv-q\left(e_{i}, e_{j}, e_{-i j}\right)$, the desert utility component of total utility $U_{i}$ now takes the following form:

$$
\frac{1}{N-1} \sum_{j \neq i} D\left(\triangle_{i j}\right),
$$

where the properties of $D\left(\triangle_{i j}\right)$ match those previously imposed on $D\left(\triangle_{i}\right)$ in Section 3.2. Thus a given pairwise comparison induces a desert loss when agent $i$ feels she deserves more than agent $j$ so $q\left(e_{i}, e_{j}, e_{-i j}\right)>0$ and hence $\triangle_{i j}<0$, and induces desert elation or guilt when $i$ feels she deserves less than $j$ so $q\left(e_{i}, e_{j}, e_{-i j}\right)<0$ and hence $\triangle_{i j}>0$. This generalization nests our earlier model of desert when we set $q\left(e_{i}, e_{j}, e_{-i j}\right)=-\left(\phi\left(y_{i}\right)-\phi\left(r_{i}\right)\right)$, so $\triangle_{i j}=\triangle_{i}=\phi\left(y_{i}\right)-\phi\left(r_{i}\right)$ for all $i, j$ pairs, and hence desert utility $\left(\sum_{j \neq i} D\left(\triangle_{i j}\right)\right) /(N-1)=D\left(\triangle_{i}\right)=D\left(\phi\left(y_{i}\right)-\phi\left(r_{i}\right)\right) .{ }^{24}$ The generalization also nests inequity aversion over money net of effort costs, given by (10), when $\phi\left(y_{i}\right)=y_{i}, \quad q\left(e_{i}, e_{j}, e_{-i j}\right)=C\left(e_{i}\right)-C\left(e_{j}\right)$ so $\triangle_{i j}=C\left(e_{j}\right)-C\left(e_{i}\right)$, and $D\left(\triangle_{i j}\right)$ takes the same piecewise-linear form as $D\left(\triangle_{i}\right)$ in the two-agent case above with $l=\alpha, g=-\beta$, and $l>g$ as $\alpha>-\beta$. Thus we get the following result.

Proposition 7 When there are more than two agents, a generalization of our model of desert to allow for pairwise desert comparisons continues to nest inequity aversion over monetary payoffs net of effort costs as a special case.

\section{Linear example}

In this section we linearize our model in order to work with an analytically tractable example. We undertake this exercise for a number of reasons. First, the analysis clarifies the more abstract results above in an applied setting. Second, we can say more in the example: in particular we can rule out asymmetric desert equilibria and we find a range of equilibria with desert elation. Third, the example allows us to get a feel for how the range of equilibria varies with the parameters of the model. Fourth, we are able to derive results about how desert concerns affect the optimal team size. Finally, we hope that the example will prove useful in future applied theoretical and empirical work.

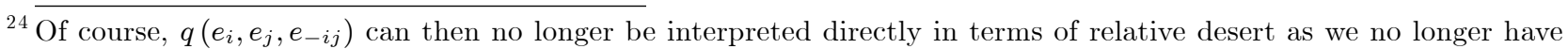
any notion of pairwise comparisons, and so we should not seek to impose (12) on it. 


\subsection{Equilibrium in the linear example}

We linearize monetary utility, so that $\phi\left(y_{i}\right)=y_{i}$, and we linearize team output as a function of efforts, so that $f\left(\sum_{i=1}^{N} e_{i}\right)=\sum_{i=1}^{N} e_{i}$. We assume that the cost of effort function is quadratic, i.e., $C\left(e_{i}\right)=\left(c e_{i}^{2}\right) / 2$ with $c>0$, so marginal cost is linearized. We further assume that the deserved reference point takes the form given by (3), with $r_{i}=0$ when $\sum_{i=1}^{N} e_{i}=0$, which gives $r_{i}=e_{i}$ due to the linearity of the team output function $f .{ }^{25}$ Finally, we assume that desert utility $D\left(\triangle_{i}\right)$ takes the piecewise-linear form described in the final paragraph of Section 3.3, so $l>0$ represents the slope of desert utility when the agent receives less than she feels she deserves and $g$ represents the slope when the agent receives more. Our assumption of loss aversion implies that $l>g$. As noted in Section 3.3, under piecewise linearity there is no distinction between local and global desert guilt or between local and global desert elation, so we will simply refer to desert guilt when $g<0$ and desert elation when $g>0$. Under these conditions, we get the following result.

\section{Proposition 8}

(i) In the absence of desert, there is a unique and symmetric pure-strategy Nash equilibrium in which the agents exert effort $\widetilde{e}=\frac{1}{c N}>0$, which is strictly lower than the socially efficient level $e^{w}=\frac{1}{c}$.

(ii) With desert, any effort $e^{*} \in\left[\frac{1}{c N}-l\left(\frac{N-1}{c N}\right), \max \left\{\frac{1}{c N}-g\left(\frac{N-1}{c N}\right), 0\right\}\right] \cap \mathbb{R}_{+}$forms a symmetric desert equilibrium. There are no other desert equilibria.

(iii) Desert guilt $(g<0)$ gives a range of symmetric desert equilibria around the equilibrium level of effort in the absence of desert $\widetilde{e}$. The top of the range tends to the socially efficient level of effort $e^{w}$ as $g$ tends to -1 .

(iv) Desert elation $(g>0)$ implies that equilibrium effort is always strictly lower than the equilibrium level in the absence of desert $\widetilde{e}$, with a range of symmetric desert equilibria when $g<$ $\frac{1}{N-1}$ and a unique symmetric desert equilibrium at zero effort when $g \geq \frac{1}{N-1}$.

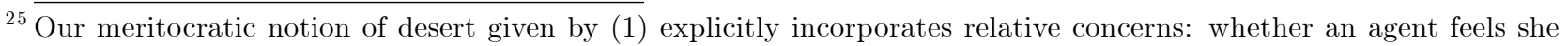
deserves more or less than a teammate depends on whether she has worked harder or less hard than that teammate. The reference point formulation given by (3) implements this by assuming that an agent feels she deserves a share of team output equal to her share of effort. The linearity of the team output function $f$ collapses this particular reference point to $r_{i}=e_{i}$. Therefore, $r_{i}$ no longer depends directly on the efforts of agent $i$ 's teammates, although the share of team output felt to be deserved, given by $e_{i} /\left(\sum_{i=1}^{N} e_{i}\right)$, continues to do so, and our general notion of desert (1) continues to be satisfied. If we had wished to use a reference point in the linear example for which $r_{i}$ continued to depend directly on the efforts of teammates, we could instead have used the following reference point: $r_{i}=k \cdot\left(e_{i}-s_{-i}\right)+\left(\sum_{i=1}^{N} e_{i}\right) / N$ for $k>0$ and $s_{-i}=\left(\sum_{j \neq i} e_{j}\right) /(N-1)$, where $k \cdot\left(e_{i}-s_{-i}\right)$ represents how much more or less than her equal share of team output the agent feels that she deserves as a linear function of the difference between her effort and the average of that of her teammates. This $r_{i}$ satisfies Assumption 1 and our general notion of desert (1), and collapses to $r_{i}=e_{i}$ only when $k=(N-1) / N$. Using this $r_{i}$, for any $k>0$ the range of desert equilibria given in Proposition 8(ii) continues to hold when we replace $l(N-1) / N$ by $l k$ and $g(N-1) / N$ by $g k$. 


\section{Proof. See Appendix.}

Part (i) corresponds to Proposition 1 for the more general model. Part (ii) gives us the range of symmetric equilibria with desert as an explicit function of the parameters of the linear example. Part (ii) also tells us that in this linear example there can be no asymmetric equilibria. We were not able to rule these out in our more general model. Part (iii) confirms Proposition 2, but further tells us that as $g$ tends to -1 , so desert utility with guilt tends to be as steep as money utility, we approach social efficiency if the agents coordinate on the highest-effort equilibrium. Part (iv) confirms Proposition 3, and also confirms that a range of equilibria exists when desert elation is not too strong.

We now look at how the range of equilibria given by part (ii) changes with the strength of desert preferences. When desert elation becomes weaker or desert guilt becomes stronger (i.e., $g$ falls), the highest feasible equilibrium level of effort goes up. When desert losses become more strongly felt (i.e., $l$ rises), the lowest feasible equilibrium level of effort goes down. With desert guilt $(g<0)$, the difference between the highest feasible equilibrium level of effort and the no-desert level as a proportion of the no-desert level $\widetilde{e}=(c N)^{-1}$ is given by $-g(N-1)>0$. This proportion is increasing in the strength of desert guilt and in the number of agents $N$.

\subsection{Optimal team size in the linear example}

Next, we apply our linear example to consider how desert concerns affect the optimal team size. ${ }^{26}$ Fixing the number of workers $N$, we ask how a principal whose objective is to maximize welfare would want to divide the agents into $T \in[1, N]$ equally sized teams. More specifically, letting team size be given by $S=N / T$, we find the team size $S \in[1, N]$ that maximizes welfare.

${ }^{26}$ Although most work on teams takes team size as given, a few papers have considered questions of optimal team size. Some of these papers assume agents with standard preferences and beliefs. Huddart and Liang (2005), for example, investigate optimal partnership size and task assignment in a setting in which the efforts partners devote to production and monitoring of other partners' productive efforts are unobservable. Ziv (1993) considers how the underlying information structure affects the number of agents a principal will employ in a moral-hazard setting, while Ziv (2000) extends the analysis by allowing the principal to choose the number of layers in the firm as well as the number of employees at each level. Liang et al. (2008) analyze how team size, monitoring activities, and incentive contracts of managers and workers interact. There are also a couple of papers that consider questions of optimal team size when agents have non-standard preferences or beliefs. Thus, Hakenes and Katolnik (2013) show that overconfidence of team members about their own skills can help to overcome the free-rider problem and increase optimal partnership size under certain conditions. Finally, and of greatest relevance to this paper, Bartling and von Siemens (2010) show that when agents are inequity averse over payoffs net of their effort costs and the sharing rule is endogenously determined, incumbent partners may veto the admission of new members who do not increase average productivity even when it would be efficient to admit them. This is because, while the incumbent partners will find it optimal to share their profits equally, it may only be worthwhile for them to expand the partnership to include a less productive member if he receives a lesser share of the profits. But if such an agent is inequity averse, this lower payout may mean that he would shirk instead of work, which in turn will make the incumbents reluctant to admit him in the first place. 
We restrict attention to the case with desert guilt, so $g<0$, and we assume that teams always succeed in coordinating on the Pareto-dominant symmetric equilibrium within the set of equilibria available to the team. To simplify the analysis, we further assume that team size does not need to be integer valued and that each team member's utility depends only her own effort and that of her teammates (so desert utility does not depend on inter-team comparisons): formally, we assume that each agent acts as if she is a member of just one team and has $S-1$ teammates, where $S$ need not be integer valued, giving her $U_{i}=y_{i}+g\left(y_{i}-r_{i}\right) \mathbf{1}_{y_{i}-r_{i}>0}+l\left(y_{i}-r_{i}\right) \mathbf{1}_{y_{i}-r_{i}<0}-\left(c e_{i}^{2}\right) / 2$, where $y_{i}=\left(e_{i}+(S-1) s_{-i}\right) / S, s_{-i}$ is the average effort of agent $i^{\prime} s$ teammates, and $r_{i}=e_{i}$ as in Section 6.1.

Without any further structure, the optimal team size $S^{*}=1$, and so the optimal number of teams $T^{*}=N$, since an agent operating alone as a single-agent team would always produce the efficient level of output $e^{w}=1 / c$. The optimality of single-agent teams is due to the fact that agents operating together in multi-agent teams create a free-rider problem with no corresponding advantage. To make the problem interesting, we now assume that splitting agents into more teams creates an exogenous cost to the principal. In particular, we assume a quadratic exogenous cost function given by $k T^{2} / 2$ for $k>0$. These costs could represent, for example, the cost of duplicated efforts and outputs when agents operate in separate teams or the administrative costs of organizing, supervising and monitoring multiple teams.

We now consider how the level of $g$, which captures the extent of desert guilt, affects the optimal team size (since we have assumed that teams coordinate on the Pareto-dominant equilibrium, the extent to which desert losses cause pain $l$ is not relevant). To be clear, we are not thinking of a principal who can influence $g$; instead, we are interested in how the level of $g$ affects the team size that the principal would want to choose in order to maximize welfare.

Proposition 9 For $g \in(-1,0)$, the optimal team size is given by $S^{*}=\min \left\{N, \frac{(g+1)^{2}+N c k}{(g+1)^{2}}\right\}$. For $g \leq-1, S^{*}=N$. As g falls, and so desert guilt becomes stronger, the optimal team size weakly rises.

Proof. See Appendix.

The intuition is straightforward. The greater the degree of desert guilt, the more the free-rider problem in teams is mitigated, assuming as we do here that the team members coordinate on the Pareto-dominant equilibrium. Thus, the greater the degree of desert guilt, the less costly it is to increase team size to avoid the exogenous cost of running multiple teams. 


\section{$7 \quad$ Heterogeneous desert preferences}

Thus far we have assumed that agents are identical. In this section, we consider what happens to our results about equilibrium behavior when agents have heterogeneous desert preferences. There are two possible dimensions of heterogeneity to consider. First, agents might exhibit different emotional responses to getting more or less than they deserve, giving rise to different desert utility functions. Second, they might operate with different conceptions of what counts as one's 'just deserts' and so have different reference point functions.

We consider first what happens when agents have different reference point functions. So long as all agents' reference points satisfy Assumption 1, all of our results about equilibria in Section 4 (that is, Propositions 2-5) continue to hold. As we noted in Section 3.3, Assumption 1 is compatible with several different conceptions of one's 'just deserts'. Proposition 2 continues to hold because, by the same logic as in the proof of the proposition for the identical-agent case, there will be an agent-specific range of common effort levels $z$ around the equilibrium level of effort in the absence of desert $\widetilde{e}$ from which agent $i$ has no incentive to deviate, given by $\left[\widetilde{e}-\underline{\epsilon}_{i}, \widetilde{e}+\bar{\epsilon}_{i}\right]$ where $\underline{\epsilon}_{i}>0$ and $\bar{\epsilon}_{i}>0$. Whereas every agent's range is the same when agents are identical, and so corresponds to the range of equilibrium efforts, when agents have different reference point functions, the $\underline{\epsilon}_{i}$ and $\bar{\epsilon}_{i}$ can vary across agents. This means that the range of symmetric desert equilibria is given by the intersection of these agent-specific ranges, where the bounds are determined by the agent with the smallest $\underline{\epsilon}_{i}$ and the agent with the smallest $\bar{\epsilon}_{i}$. The proof of Proposition 4 extends in analogous way to that of Proposition 2, noting that $\lambda_{g}$ needs to be small enough that no agent has an incentive to deviate downward. The proofs of Propositions 3 and 5 extend immediately.

Similarly, our results in Section 4 continue to hold when agents have different desert utility functions, if all agents exhibit either desert guilt or desert elation. Propositions 2 and 5 hold when all agents exhibit desert guilt and Propositions 3, 4 and 5(ii) hold when all agents exhibit desert elation. Proposition 3 extends to the case where some agents exhibit desert guilt but others exhibit desert elation: any agent who exhibits desert elation has an incentive to undercut common effort levels at or above the equilibrium level of effort in the absence of desert $\widetilde{e}$, since by doing so she gains elation from receiving more than she feel she deserves. This suggests that a principal who can choose the composition of different work teams should concentrate agents who exhibit desert elation in the same team so that they do not disrupt more efficient equilibria that can be sustained among agents that all exhibit desert guilt. 


\section{Conclusion}

In this paper we developed a theoretical framework to study the strategic implications of desert considerations when agents work in teams. Our notion of desert can be seen as a generalization of distributional concern models to situations in which effort choices affect the distribution that is perceived to be fair or equitable. We have focused on the strategic implications of desert for the team members themselves. However, we hope that our framework and insights will provide a useful building block for future research evaluating optimal responses by various actors to agents' desert concerns, e.g., employers deciding whether or not to use teams in the workplace and designing team incentive schemes given employees with desert concerns, policy-makers deciding how to tax partnerships and team-based bonuses when participants have desert concerns, and workers deciding whether or not to join teams given their own and others' desert concerns.

Our main result is that desert concerns create multiple equilibria when agents face team incentives, which, when agents suffer from desert guilt, include equilibria that approach or even exceed the efficient effort level. Thus, at least to the extent that agents are able to coordinate on high-effort equilibria, we should expect free-riding to be less of a problem when agents are motivated to ensure that they don't get more than they deserve. We also found that, when there are exogenous costs to splitting agents into more teams, the optimal team size increases in the strength of desert guilt. Thus, employers and workers alike have reason to embrace team incentive schemes when equitable norms are pervasive, and they have reason to promote transparency about individual team members' contributions to the team output in order to facilitate coordination on superior equilibria. It is important that the equitable norms are pervasive, if the advantages of desert concerns are to be realized, since agents who enjoy getting more than they deserve disrupt the superior equilibria. So workers who have properly internalized equitable norms will be more likely to join teams that are full of like-minded agents, and employers have reason to ensure that any renegade agents are kept apart from those who have properly internalized such norms.

In addition to providing a building block for future theoretical research that improves our understanding of the use of team incentives in the workplace beyond the insights that we have developed here, we hope that our model will spur testing to determine whether agents who interact in teams behave as if desert concerns matter to them. Finally, we hope that researchers will use our framework to analyze the equilibrium implications of desert in broader settings where, for instance, teammates interact repeatedly, or simultaneously cooperate in teams but compete for promotions. 


\section{Appendix}

Proof of Proposition 1. For any vector of efforts $e_{-i}$ for the other team members:

$$
\begin{aligned}
\bar{U}_{i}^{\prime} & \equiv \frac{\partial \bar{U}_{i}}{\partial e_{i}}=\phi^{\prime}\left(\frac{f}{N}\right) \frac{f^{\prime}}{N}-C^{\prime} \\
\bar{U}_{i}^{\prime \prime} & \equiv \frac{\partial^{2} \bar{U}_{i}}{\partial e_{i}^{2}}=\phi^{\prime \prime}\left(\frac{f}{N}\right)\left(\frac{f^{\prime}}{N}\right)^{2}+\phi^{\prime}\left(\frac{f}{N}\right) \frac{f^{\prime \prime}}{N}-C^{\prime \prime}<0 .
\end{aligned}
$$

Thus for any $e_{-i}, \bar{U}_{i}$ is strictly concave; and furthermore $\bar{U}_{i}^{\prime}<0$ for high enough $e_{i}$ given that $C^{\prime}$ is unbounded above. Therefore a strict best response $e_{i}^{*}$ exists and is unique for any $e_{-i}$.

No asymmetric equilibrium can exist. Suppose one did. The agent(s) with the highest effort must have $\bar{U}_{i}^{\prime}=0$. Any agent with a strictly lower effort will share the same $\phi^{\prime}\left(\frac{f}{N}\right) \frac{f^{\prime}}{N}$ and have a strictly lower $C^{\prime}$ and so will have a strict incentive to increase effort.

Differentiating $\bar{U}_{i}^{\prime}$ w.r.t. a common effort level $z$ :

$$
\frac{\partial \bar{U}_{i}^{\prime}}{\partial z}=\phi^{\prime \prime}\left(\frac{f(N z)}{N}\right)\left(\frac{f^{\prime}(N z)}{N}\right)^{2} N+\phi^{\prime}\left(\frac{f(N z)}{N}\right) \frac{f^{\prime \prime}(N z)}{N} N-C^{\prime \prime}(z)<0
$$

Thus a unique symmetric equilibrium $\widetilde{e}>0$ exists where $\widetilde{e}=C^{\prime-1}\left(\phi^{\prime}\left(\frac{f(N \widetilde{e})}{N}\right) \frac{f^{\prime}(N \widetilde{e})}{N}\right)$, as $\bar{U}_{i}^{\prime}>0$ for $z=0$ while $\bar{U}_{i}^{\prime}<0$ for high enough $z$ given that $C^{\prime}$ is unbounded above.

Consider now the socially optimal vector of efforts. Because $C^{\prime \prime}>0$ and $Y$ depends on $\sum_{i=1}^{N} e_{i}$, all the agents' efforts must be the same at a social optimum. At a common effort level $z$ :

$$
\begin{aligned}
\frac{\partial W}{\partial z} & =N\left(\phi^{\prime}\left(\frac{f(N z)}{N}\right) \frac{f^{\prime}(N z)}{N} N-C^{\prime}(z)\right) \\
\frac{\partial^{2} W}{\partial z^{2}} & =N\left(\phi^{\prime \prime}\left(\frac{f(N z)}{N}\right)\left(\frac{f^{\prime}(N z)}{N}\right)^{2} N^{2}+\phi^{\prime}\left(\frac{f(N z)}{N}\right) \frac{f^{\prime \prime}(N z)}{N} N^{2}-C^{\prime \prime}(z)\right)<0
\end{aligned}
$$

Any social optimum must have $e^{w}>\widetilde{e}$, as at $z=\widetilde{e} \frac{\partial W}{\partial z}>0$. A unique optimum must exist where $e^{w}=C^{\prime-1}\left(\phi^{\prime}\left(\frac{f\left(N e^{w}\right)}{N}\right) \frac{f^{\prime}\left(N e^{w}\right)}{N} N\right)$, as $W$ is strictly concave in $z$ and $\frac{\partial W}{\partial z}<0$ for high enough $z$ given that $C^{\prime}$ is unbounded above.

Proof of Proposition 2. Consider agent $i$ 's incentive to deviate from a common effort level $z>0$. We show that for any $z$ sufficiently close to the no-desert equilibrium effort $\widetilde{e}>0$, the reduction in $i^{\prime} s$ desert utility $D\left(\triangle_{i}\right)$ arising from such a deviation outweighs any gain in standard utility $\bar{U}_{i}$, so $e_{i}=z$ is a best response to $z_{-i}$, that is to the vector of others' efforts $e_{-i}$ in which $e_{j}=z \quad \forall j \neq i$. 
From Assumption 1(i) and $\phi^{\prime}>0, \triangle_{i} \gtreqless 0 \Leftrightarrow y_{i} \gtreqless r_{i} \Leftrightarrow e_{i} \lesseqgtr z$. Thus $e_{i}=z \Rightarrow D\left(\triangle_{i}\right)=$ $D(0)=0$, while a deviation upward to $e_{i}>z \Rightarrow D\left(\triangle_{i}\right)<0$ as $L\left(\triangle_{i}\right)<0$ for $\triangle_{i}<0$, and a deviation downward to $e_{i}<z \Rightarrow D\left(\triangle_{i}\right)<0$ as $G\left(\triangle_{i}\right)<0$ for $\triangle_{i}>0$ by the assumption of global desert guilt. Thus any deviation strictly reduces $D$, so deviations must increase $\bar{U}_{i}$ sufficiently to compensate.

(a) First consider $z \in(0, \widetilde{e}]$. From the proof of Proposition $1, \bar{U}_{i}^{\prime \prime}<0$ with $\bar{U}_{i}^{\prime}<0$ for $e_{i}$ sufficiently high, and $\bar{U}_{i}^{\prime}\left(z, z_{-i}\right) \geq 0$ given $z \leq \widetilde{e}$. Thus downward deviations strictly reduce $\bar{U}_{i}$, while the strict concavity of $\bar{U}_{i}$ in $e_{i}$ and its continuity in $z$ ensures that large enough upward deviations must always reduce $\bar{U}_{i}$, i.e., $\exists \widehat{e}>\widetilde{e}$ such that $\forall z \leq \widetilde{e}, \bar{U}_{i}\left(e_{i}, z_{-i}\right) \geq \bar{U}_{i}\left(z, z_{-i}\right) \Rightarrow e_{i} \in[z, \widehat{e}]$. As all deviations strictly reduce $D$, we can therefore restrict attention to deviations with $e_{i} \in(z, \widehat{e}]$.

Now take a given $z \in(0, \widetilde{e}]$. The gain in $\bar{U}_{i}$ from deviating to a specific $e_{i} \in(z, \widehat{e}]$ is bounded above by $\bar{U}_{i}^{\prime}\left(z, z_{-i}\right)\left(e_{i}-z\right)$ given $\bar{U}_{i}^{\prime \prime}<0$. The desert loss from a deviation to the specific $e_{i} \in(z, \widehat{e}]$, $D\left(\triangle_{i}\right)<0$, is bounded above by $\left(\sup _{e_{i} \in(z, \widehat{e}]} \frac{D\left(\triangle_{i}\right)}{e_{i}-z}\right)\left(e_{i}-z\right)$. If $\frac{D\left(\triangle_{i}\right)}{e_{i}-z}$ has a maximal value $m(z)$ over $e_{i} \in(z, \widehat{e}]$, then $\sup _{e_{i} \in(z, \widehat{e}]} \frac{D\left(\triangle_{i}\right)}{e_{i}-z}=m(z)<0$. If not, $\sup _{e_{i} \in(z, \widehat{e}]} \frac{D\left(\triangle_{i}\right)}{e_{i}-z}=\lim _{e_{i} \downarrow z} \frac{D\left(\triangle_{i}\right)}{e_{i}-z}$. Applying L'Hôpital's Rule, and using Assumption 1 and $L^{\prime}(0)>0$ :

$$
\begin{aligned}
\lim _{e_{i} \downarrow z} \frac{D\left(\triangle_{i}\right)}{e_{i}-z} & =\lim _{e_{i} \downarrow z} D^{\prime}\left(\phi\left(\frac{f}{N}\right)-\phi\left(r_{i}\right)\right)\left(\phi^{\prime}\left(\frac{f}{N}\right) \frac{f^{\prime}}{N}-\phi^{\prime}\left(r_{i}\right) r_{i}^{\prime}\right) \\
& =L^{\prime}(0)\left(\phi^{\prime}\left(\frac{f(N z)}{N}\right)\left(\frac{f^{\prime}(N z)}{N}-r_{i}^{\prime}\left(z, z_{-i}\right)\right)\right)<0 .
\end{aligned}
$$

Thus, as a sufficient condition, deviation to any $e_{i} \in(z, \widehat{e}]$ strictly reduces $U_{i}$ if $\bar{U}_{i}^{\prime}\left(z, z_{-i}\right)<$ $-\sup _{e_{i} \in(z, \widehat{e}]} \frac{D\left(\triangle_{i}\right)}{e_{i}-z}$. From the proof of Proposition $1, \bar{U}_{i}^{\prime}\left(\widetilde{e}, \widetilde{e}_{-i}\right)=0$, and therefore by continuity $\lim _{z \uparrow \widetilde{e}} \bar{U}_{i}^{\prime}\left(z, z_{-i}\right)=0$. By continuity, $\lim _{z \uparrow \widetilde{e}}\left(-\sup _{e_{i} \in(z, \widehat{e}]} \frac{D\left(\triangle_{i}\right)}{e_{i}-z}\right)=-\sup _{e_{i} \in(\widetilde{e}, \widehat{e}]} \frac{D\left(\triangle_{i}\right)}{e_{i}-\widetilde{e}}$. In turn, we can see that $-\sup _{e_{i} \in(\widetilde{e}, \widetilde{e}} \frac{D\left(\triangle_{i}\right)}{e_{i}-\widetilde{e}}>0$, as the sup either equals $m(\widetilde{e})<0$ if such a maximal value exists, or $L^{\prime}(0)\left(\phi^{\prime}\left(\frac{f(N \widetilde{e})}{N}\right)\left(\frac{f^{\prime}(N \widetilde{e})}{N}-r_{i}^{\prime}\left(\widetilde{e}, \widetilde{e}_{-i}\right)\right)\right)<0$. Thus for $z$ sufficiently close to $\widetilde{e}$, and for $z=\widetilde{e}$, all deviations strictly reduce $U_{i}$ so we have a (strict) equilibrium.

(b) When considering $z>\widetilde{e}$, a similar argument to (a) holds, inverting the directions of deviations. $\bar{U}_{i}^{\prime}\left(z, z_{-i}\right)<0$ given $z>\widetilde{e}$. As $\bar{U}_{i}^{\prime \prime}<0$, we need only consider downward deviations, which in this case have a natural bound at 0 . The sufficient no-deviation condition in this case is $-\bar{U}_{i}^{\prime}\left(z, z_{-i}\right)<-\sup _{e_{i} \in[0, z)} \frac{D\left(\triangle_{i}\right)}{z-e_{i}}$, and $\lim _{e_{i} \uparrow z} \frac{D\left(\triangle_{i}\right)}{z-e_{i}}=-G^{\prime}(0) \phi^{\prime}\left(\frac{f(N z)}{N}\right)\left(\frac{f^{\prime}(N z)}{N}-r_{i}^{\prime}\left(z, z_{-i}\right)\right)<0$ using Assumption 1 and $G^{\prime}(0)<0$ from global desert guilt. 
Proof of Proposition 3. Suppose we have a common effort level $z \geq \widetilde{e}$. From the proof of Proposition $1, \bar{U}_{i}^{\prime}\left(z, z_{-i}\right) \leq 0$ given $z \geq \widetilde{e}$. Applying L'Hôpital's Rule and using Assumption 1 together with $G^{\prime}(0)>0$ from local desert elation:

$$
\begin{aligned}
\lim _{e_{i} \uparrow z} \frac{D\left(\triangle_{i}\right)-0}{e_{i}-z} & =\lim _{e_{i} \uparrow z} D^{\prime}\left(\phi\left(\frac{f}{N}\right)-\phi\left(r_{i}\right)\right)\left(\phi^{\prime}\left(\frac{f}{N}\right) \frac{f^{\prime}}{N}-\phi^{\prime}\left(r_{i}\right) r_{i}^{\prime}\right) \\
& =G^{\prime}(0)\left(\phi^{\prime}\left(\frac{f(N z)}{N}\right)\left(\frac{f^{\prime}(N z)}{N}-r_{i}^{\prime}\left(z, z_{-i}\right)\right)\right)<0 .
\end{aligned}
$$

Thus local downward deviations strictly increase $U_{i}$, so we cannot have an equilibrium.

Proof of Proposition 4. Part (a) of the proof of Proposition 2 shows that, given a common effort level $z<\widetilde{e}$, an upward deviation from $z$ strictly reduces $U_{i}$ when $z$ is close enough to $\widetilde{e}$. Take a given $\widehat{z}<\widetilde{e}$ that lies strictly within the range of $z$ for which there is no upward deviation incentive. From the proof of Proposition $1, \bar{U}_{i}^{\prime \prime}<0$ and $\bar{U}_{i}^{\prime}\left(\widehat{z}, \widehat{z}_{-i}\right)>0$ since $\widehat{z}<\widetilde{e}$. Thus, the loss in $\bar{U}_{i}$ from deviating downward to a specific $e_{i} \in[0, \widehat{z})$ is bounded above by $-\bar{U}_{i}^{\prime}\left(\widehat{z}, \widehat{z}_{-i}\right)\left(\widehat{z}-e_{i}\right)<0$ while the gain in desert elation is bounded by $\left(\sup _{e_{i} \in[0, \widehat{z})} \frac{\mathcal{D}\left(\triangle_{i}, \lambda_{l}, \lambda_{g}\right)}{\widehat{z}-e_{i}}\right)\left(\widehat{z}-e_{i}\right)$. Therefore, in this case the sufficient condition for any downward deviation to strictly reduce $U_{i}$ is given by $\bar{U}_{i}^{\prime}\left(\widehat{z}, \widehat{z}_{-i}\right)>$ $\sup _{e_{i} \in[0, \widehat{z})} \frac{\mathcal{D}\left(\triangle_{i}, \lambda_{l}, \lambda_{g}\right)}{\widehat{z}-e_{i}}$. Now,

$$
\sup _{e_{i} \in[0, \widehat{z})} \frac{\mathcal{D}\left(\triangle_{i}, \lambda_{l}, \lambda_{g}\right)}{\widehat{z}-e_{i}}=\sup _{e_{i} \in[0, \widehat{z})} \frac{\lambda_{g} G\left(\triangle_{i}\right)}{\widehat{z}-e_{i}}=\lambda_{g} \sup _{e_{i} \in[0, \widehat{z})} \frac{G\left(\triangle_{i}\right)}{\widehat{z}-e_{i}}
$$

Thus, $\lim _{\lambda_{g} \downarrow 0}\left(\sup _{e_{i} \in[0, \widehat{z})} \frac{\mathcal{D}\left(\triangle_{i}, \lambda_{l}, \lambda_{g}\right)}{\widehat{z}-e_{i}}\right)=0$, and hence the no-downward-deviation condition is satisfied when $\lambda_{g}$ is sufficiently close to 0 (noting that $\sup _{e_{i} \in[0, \widehat{z})} \frac{G\left(\triangle_{i}\right)}{\widehat{z}-e_{i}}$ must exist, since $\lim _{e_{i} \uparrow \widehat{z}} \frac{G\left(\triangle_{i}\right)}{\widehat{z}-e_{i}}=$ $\left.-G^{\prime}(0) \phi^{\prime}\left(\frac{f(N \widehat{z})}{N}\right)\left(\frac{f^{\prime}(N \widehat{z})}{N}-r_{i}^{\prime}\left(\widehat{z}, \widehat{z}_{-i}\right)\right)\right)$. By continuity, the sufficient no-downward-deviation condition continues to hold for a range of common effort levels $z$ around $\widehat{z}$, and by construction $\widehat{z}$ lies strictly within the range of $z$ for which there is no incentive to deviate upward. Thus, a range of (strict) symmetric equilibria exists for $\lambda_{g}$ sufficiently small. Finally, from Proposition 3 all the equilibria must be strictly below $\widetilde{e}$.

Proof of Proposition 5. Note first that if the agents exhibit global desert guilt (Definition $1)$, desert utility $D\left(\triangle_{i}\right) \leq 0$ at any vector of efforts. Note second that when the agents all exert a common effort level $z>0, D\left(\triangle_{i}\right)=0$ : from Assumption 1 each agent's deserved reference point matches the equal share of team output that she receives, so $\triangle_{i}=0$. Part (i) then follows as when all agents exert the socially optimal level of effort in the absence of desert, given by $e^{w}>0$ from 
Proposition 1, the sum of standard utilities $\sum_{i=1}^{N} \bar{U}_{i}$ is maximized and $D\left(\triangle_{i}\right)=0$, so $W=\sum_{i=1}^{N} U_{i}$ is maximized also.

Next note that, from (18), welfare in the absence of desert is strictly concave in a common effort level $z$ around $e^{w}$. When considering $z>0$ in a symmetric desert equilibrium, $D\left(\triangle_{i}\right)=0$ from above, so welfare with desert preference matches welfare without desert. Thus Part (ii) follows immediately from this concavity.

\section{Proof of Proposition 8.}

(i) Follows immediately from Proposition 1 and the expressions for $\widetilde{e}$ and $e^{w}$ in its proof.

(ii) Let $s_{-i} \equiv \frac{\sum_{j \neq i} e_{j}}{N-1}$. If agent $i$ sets $e_{i}>s_{-i}$, then $y_{i}=\frac{e_{i}+(N-1) s_{-i}}{N}<e_{i}=r_{i}$ so the agent suffers a desert loss and $U_{i}=\frac{e_{i}+(N-1) s_{-i}}{N}+l\left(\frac{e_{i}+(N-1) s_{-i}}{N}-e_{i}\right)-\frac{c e_{i}^{2}}{2}$. If $e_{i}<s_{-i}$, then $y_{i}>e_{i}=r_{i}$ and the agent feels desert elation or guilt with $U_{i}=\frac{e_{i}+(N-1) s_{-i}}{N}+g\left(\frac{e_{i}+(N-1) s_{-i}}{N}-e_{i}\right)-\frac{c e_{i}^{2}}{2}$. If $e_{i}=s_{-i}, y_{i}=e_{i}=r_{i}$ so $U_{i}=\frac{e_{i}+(N-1) s_{-i}}{N}-\frac{c e_{i}^{2}}{2}$.

At $e_{i}=s_{-i}$, the right-hand side derivative $\left(\frac{\partial U_{i}}{\partial e_{i}}\right)^{+}=\frac{1}{N}-l\left(\frac{N-1}{N}\right)-c e_{i} \leq 0 \Leftrightarrow \frac{1}{c N}-l\left(\frac{N-1}{c N}\right) \leq e_{i}$. At $e_{i}=s_{-i}$, the left-hand side derivative $\left(\frac{\partial U_{i}}{\partial e_{i}}\right)^{-}=\frac{1}{N}-g\left(\frac{N-1}{N}\right)-c e_{i} \geq 0 \Leftrightarrow \frac{1}{c N}-g\left(\frac{N-1}{c N}\right) \geq e_{i}$. Furthermore, $U_{i}$ is everywhere strictly concave. Remembering that $e_{i} \geq 0$ and that $l>g$ from our assumption of loss aversion, it follows that any $e^{*} \in\left[\frac{1}{c N}-l\left(\frac{N-1}{c N}\right), \max \left\{\frac{1}{c N}-g\left(\frac{N-1}{c N}\right), 0\right\}\right] \cap \mathbb{R}_{+}$ forms a symmetric desert equilibrium and that there can be no other symmetric desert equilibria.

Suppose now that an asymmetric desert equilibrium exists. Let $e_{i}^{\max }$ represent the highest equilibrium effort. Then $e_{i}^{\max }>s_{-i}$ and $e_{i}^{\max }>0$, so $e_{i}^{\max }=\frac{1}{c N}-l\left(\frac{N-1}{c N}\right)>0$ given $U_{i}$ is everywhere strictly concave. Similarly, $e_{i}^{\min }<s_{-i}$, so $e_{i}^{\min }=\max \left\{\frac{1}{c N}-g\left(\frac{N-1}{c N}\right), 0\right\}$. But this gives a contradiction given $l>g$ and $e_{i}^{\max }>e_{i}^{\min }$, so there can be no asymmetric desert equilibria.

(iii) Follows immediately from parts (i) and (ii) given $l>0$ and $g<0$.

(iv) Follows immediately from parts (i) and (ii) given $l>g>0$.

Proof of Proposition 9. By an argument analogous to that in the proof of Proposition 8(ii), the range of symmetric equilibria is the same as given in Proposition 8(ii), replacing $N$ with $S$.

Suppose first that $g \in(-1,0)$. Given we have assumed that agents coordinate on the Paretodominant symmetric equilibrium, and given $S=\frac{N}{T}$, equilibrium effort is:

$$
e^{*}=\frac{1}{c S}-g\left(\frac{S-1}{c S}\right)=\frac{(g+1)-S g}{S c}=\frac{T(g+1)-N g}{N c} .
$$

In this symmetric equilibrium, $y_{i}=r_{i}=e^{*}$, and so team welfare is given by $S\left(e^{*}-\frac{c\left(e^{*}\right)^{2}}{2}\right)$. There 
are $\frac{N}{S}$ such teams, so overall welfare is given by:

$$
W=N\left(\frac{T(g+1)-N g}{N c}\right)-N \frac{c\left(\frac{T(g+1)-N g}{N c}\right)^{2}}{2}-\frac{k T^{2}}{2} .
$$

The first-order condition is

$$
\frac{\partial W}{\partial T}=\frac{1}{c}(g+1)-\frac{1}{N c}(T(g+1)-N g)(g+1)-T k=0,
$$

which is satisfied when $T=\frac{(g+1)^{2} N}{(g+1)^{2}+N c k}$. Welfare is strictly concave since $\frac{\partial^{2} W}{\partial T^{2}}=-\frac{1}{N c}(g+1)^{2}-k<$ 0 . Therefore, the first-order condition implies that $T^{*}=\max \left\{1, \frac{(g+1)^{2} N}{(g+1)^{2}+N c k}\right\}$, given $T \in[1, N]$ and $\frac{(g+1)^{2} N}{(g+1)^{2}+N c k}<N$. Thus, $S^{*}=N / T^{*}=\min \left\{N, \frac{(g+1)^{2}+N c k}{(g+1)^{2}}\right\}$. Finally, $S^{*}$ is weakly decreasing in $g$ given

$$
\frac{\partial\left(\frac{(g+1)^{2}+N c k}{(g+1)^{2}}\right)}{\partial g}=\frac{-2 N c k}{(g+1)^{3}}<0 .
$$

Suppose second that $g \leq-1$. Then $e^{*}=e^{w}=\frac{1}{c}$ given agents coordinate on the Pareto-dominant symmetric equilibrium. Thus, $S^{*}=N$ since any $S$ maximizes welfare net of the exogenous team cost, but $S^{*}=N$ minimizes the team cost. 


\section{References}

Abeler, J., Altmann, S., Kube, S. and Wibral, M. (2010). "Gift Exchange and Workers' Fairness Concerns - When Equality is Unfair". Journal of the European Economic Association, 8(6), 1299-1324.

Adams, J.S. (1965). "Inequity in Social Exchange". In "Advances in Experimental Social Psychology, Volume 2", Berkowitz, L. (Ed.), New York: Academic Press, 267-299.

Akerlof, G.A. and Yellen, J.L. (1990). "The Fair Wage-Effort Hypothesis and Unemployment". Quarterly Journal of Economics, 105(2), 255-283.

Almås, I., Cappelen, A.W., Lind, J.T., Sørensen. E. Ø. and Tungodden, B. (2011). "Measuring Unfair (In)equality". Journal of Public Economics, 95(7-8), 488-499.

Ausubel, D.P. (1955). "Relationships between Shame and Guilt in the Socializing Process". Psychological Review, 62(5), 378-390.

Babcock, P., Bedard, K., Charness, G., Hartman, J., and Royer, H. (2011), "Letting Down the Team? Evidence of Social Effects of Team Incentives". NBER Working Paper No. 16687.

Bartling, B. (2011). "Relative Performance or Team Evaluation? Optimal Contracts for Other-Regarding Agents". Journal of Economic Behavior and Organization, 79(3), 183-193.

Bartling, B. and von Siemens, F. (2010). "Equal Sharing Rules in Partnerships". Journal of Institutional and Theoretical Economics, 166(2), 299-320.

Battigalli, P. and Dufwenberg, M. (2007). "Guilt in Games". American Economic Review: Papers and Proceedings, 97(2), 170-176.

Battigalli, P. and Dufwenberg, M. (2009). "Dynamic Psychological Games". Journal of Economic Theory, 144(1), 1-35.

Bicchieri, C. (2006). "The Grammar of Society: The Nature and Dynamics of Social Norms". Cambridge: Cambridge University Press.

Bolton, G.E. and Ockenfels, A. (2000). "ERC: A Theory of Equity, Reciprocity and Competition". American Economic Review, 90(1), 166-193.

Boning, B., Ichniowski, C., and Shaw, K. (2007). "Opportunity Counts: Teams and the Effectiveness of Production Incentives". Journal of Labor Economics, 25(4), 613-650.

Bossert, W. (1995). "Redistribution Mechanisms Based on Individual Characteristics". Mathematical Social Sciences, 29(1), 1-17.

Bossert, W. and Fleurbaey, M. (1996). "Redistribution and Compensation". Social Choice and Welfare, $13(3), 343-355$.

Cappelen, A.W., Hole, A.D., Sørensen, E.O. and Tungodden, B. (2007). "The Pluralism of Fairness Ideals: An Experimental Approach". American Economic Review, 97(3), 818-827.

Cason, T.N., Saijo, T. and Yamato, T. (2002). "Voluntary Participation and Spite in Public Good Provision Experiments: An International Comparison". Experimental Economics, 5(3), 133-153.

Cason, T.N., Saijo, T., Yamato, T. and Yokotani, K. (2004). "Non-Excludable Public Good Experiments". Games and Economic Behavior, 49(1), 81-102.

Che, Y.-K. and Yoo, S.-W. (2001). "Optimal Incentives for Teams". American Economic Review, 91(3), 525-541. 
Corgnet, B., Hernan-Gonzalez, R. and Rassenti, S. (2011). "Real Effort, Real Leisure and Real-time Supervision: Incentives and Peer Pressure in Virtual Organizations", Chapman University Economic Science Institute Working Papers 11-05.

Corgnet, B., Hernan-Gonzalez, R. and Rassenti, S. (2013). "Peer Pressure and Moral Hazard in Teams: Experimental Evidence", Mimeo, Chapman University.

Crawford, V.P. and Meng, J. (2011), "New York City Cabdrivers' Labor Supply Revisited: ReferenceDependent Preferences with Rational-Expectations Targets for Hours and Income". American Economic Review, 101(5), 1912-1932.

Croson, R.T.A. (2007). "Theories of Commitment, Altruism and Reciprocity: Evidence from Linear Public Goods Games". Economic Inquiry, 45(2), 199-216.

Daido, K. and Murooka, T. (2011). "Team Incentives and Reference-Dependent Preferences". Kwansei Gakuin University Discussion Paper 70.

DellaVigna, S. (2009). "Psychology and Economics: Evidence from the Field". Journal of Economic Literature, 47(2), 315-372.

Demougin, D. and Fluet, C. (2003). "Inequity Aversion in Tournaments". CIRPEE Working Paper 03-22.

Demougin, D. and Fluet, C. (2006). "Group vs. Individual Performance Pay when Workers are Envious". In "Contributions to Entrepreneurship and Economics", Demougin, D. and Schade, C. (Eds.), Berlin: Duncker \& Humblot, 39-47.

Demougin, D., Fluet, C. and Helm, C. (2006). "Output and Wages with Inequality Averse Agents". Canadian Journal of Economics, 39(2), 399-413.

Desiraju, R. and Sappington, D.E.M. (2007). "Equity and Adverse Selection". Journal of Economics and Management Strategy, 16(2), 285-318.

van Dijk, F., Sonnemans, J. and van Winden, F. (2001). "Incentive Systems in a Real Effort Experiment". European Economic Review, 45(2), 187-214.

Dufwenberg, M. and Kirchsteiger, G. (2004). "A Theory of Sequential Reciprocity". Games and Economic Behavior, 47(2), 268-298.

Eisenkopf, G. and Teyssier, S. (2013). "Envy and Loss Aversion in Tournaments". Journal of Economic Psychology, 34, 240-255.

Encinosa III, W.E., Gaynor, M. and Rebitzer, J.B. (2007). "The Sociology of Groups and the Economics of Incentives: Theory and Evidence on Compensation Systems". Journal of Economic Behavior and Organization, 62, 187-214.

Falk, A. and Fischbacher, U. (2006). "A Theory of Reciprocity". Games and Economic Behavior, 54(2), 293-315.

Falk, A., Fischbacher, U. and Gächter, S. (2013). "Living in Two Neighborhoods - Social Interactions Effects in the Laboratory". Economic Inquiry, 51(1), 563-578.

Farrell, J. and Scotchmer, S. (1988). "Partnerships". Quarterly Journal of Economics, 103(2), 279-297.

Fehr, E. and Schmidt, K. (1999). "A Theory of Fairness, Competition and Cooperation". Quarterly Journal of Economics, 114(3), 817-868.

Fershtman, C., Gneezy, U. and List, J. (2012). "Equity Aversion: Social Norms and the Desire to be Ahead". American Economic Journal: Microeconomics, 4(4), 131-144.

Fischbacher, U. and Gächter, S. (2010), "Social Preferences, Beliefs, and the Dynamics of Free Riding in Public Goods Experiments". American Economic Review, 100(1), 541-556. 
Fischbacher, U., Gächter, S. and Fehr, E. (2001). "Are People Conditionally Cooperative? Evidence from a Public Goods Experiment". Economics Letters, 71(3), 397-404.

Frohlich, N., Oppenheimer, J. and Kurki, A. (2004). "Modeling Other-Regarding Preferences and an Experimental Test". Public Choice, 119(1-2), 91-117.

Gantner, A. Güth, W. and Königstein, M. (2001). "Equitable Choices in Bargaining Games with Joint Production". Journal of Economic Behavior and Organization, 46(2), 209-225.

Geanakoplos, J., Pearce D. and Stacchetti, E. (1989). "Psychological Games and Sequential Rationality". Games and Economic Behavior, 1(1), 60-79.

Gill, D. and Prowse, V. (2012). "A Structural Analysis of Disappointment Aversion in a Real Effort Competition". American Economic Review, 102(1), 469-503.

Gill, D. and Stone, R. (2010). "Fairness and Desert in Tournaments". Games and Economic Behavior, 69(2), 346-64.

Hakenes, H. and Katolnik, S. (2013). "Optimal Team Size and Overconfidence". Mimeo, University of Bonn.

Hamilton, B.H., Nickerson, J.A. and Owan, H. (2003). "Team Incentives and Worker Heterogeneity: An Empirical Analysis of the Impact of Teams on Productivity and Participation". Journal of Political Economy, 111(3), 465-497.

Holmstrom, B. (1982). "Moral Hazard in Teams". Bell Journal of Economics, 13(2), 324-340.

Huck, S., Kübler, D. and Weibull, J. (2012). "Social Norms and Economic Incentives in Firms". Journal of Economic Behavior and Organization, 83(2), 173-185.

Huddart, S. and Liang, P.J. (2005). "Profit Sharing and Monitoring in Partnerships". Journal of Accounting and Economics, 40(1-3), 153-187.

Isaac, R.M. and Walker, J.M. (1998). "Nash as an Organizing Principle in the Voluntary Provision of Public Goods: Experimental Evidence". Experimental Economics, 1(3), 191-206.

Itoh, H. (2004). "Moral Hazard and Other-Regarding Preferences". Japanese Economic Review, 55(1), $18-45$.

Kahneman, D. and A. Tversky (1979). "Prospect Theory: An analysis of Decision under Risk". Econometrica, 47(2), 263-291.

Kandel, E. and Lazear, E.P. (1992). "Peer Pressure and Partnerships". Journal of Political Economy, $100(4), 801-817$.

Knez, M. and Simester, D. (2001). "Firm-Wide Incentives and Mutual Monitoring at Continental Airlines". Journal of Labor Economics, 19(4), 743-772.

Kölle, F., Sliwka, D. and Zhou, N. (2011). "Inequality, Inequity Aversion, and the Provision of Public Goods". IZA Discussion Paper 5514.

Konow, J. (1996). "A Positive Theory of Economic Fairness". Journal of Economic Behavior and Organization. $31,13-35$.

Konow, J. (2000). "Fair Shares: Accountability and Cognitive Dissonance in Allocation Decisions". American Economic Review, 90(4), 1072-1091.

Kőszegi, B. and Rabin, M. (2006). "A Model of Reference-Dependent Preferences". Quarterly Journal of Economics, 121(4), 1133-1165. 
Kőszegi, B. and Rabin, M. (2007). "Reference-Dependent Risk Attitudes". American Economic Review, 97(4), 1047-1073.

Krupka, E.L. and Weber, R.A. (2009). "The Focusing and Informational Effects of Norms on Pro-Social Behavior". Journal of Economic Psychology, 30(3), 307-320.

Krupka, E.L. and Weber, R.A. (2013). "Identifying Social Norms Using Coordination Games: Why Does Dictator Game Sharing Vary?" Journal of the European Economic Association, 11(3), 495-524

Kuhn, P. and Villeval, M.C. (forthcoming). "Are Women More Attracted to Cooperation than Men?" Economic Journal.

Kvaløy, O. and Olsen, T.E. (2006). "Team Incentives in Relational Employment Contracts". Journal of Labor Economics, 24(1): 139-169.

Laury, S.K. and Holt, C.A. (2008). "Voluntary Provision of Public Goods: Experimental Results with Interior Nash Equilibria". In "Handbook of Experimental Economics Results, Volume 1", Plott, C. and Smith, V. (Eds.), Amsterdam: North-Holland, 792-801.

Lawler III, E.E. and Jenkins Jr., G.D. (1992), "Strategic Reward Systems". In "Handbook of Industrial and Organizational Psychology, 2nd edition, Volume 3", Dunnette, M.D. and Hough, L.M. (Eds.), Palo Alto: Consulting Psychologists Press, Ch. 16.

Liang, P.J., Rajan, M.V. and Ray K. (2008). "Optimal Team Size and Monitoring in Organizations". Accounting Review, 83(3), 789-822.

Mohnen, A., Pokorny, K. and Sliwka, D. (2008). "Transparency, Inequity Aversion, and the Dynamics of Peer Pressure in Teams: Theory and Evidence". Journal of Labor Economics, 26(4), 693-720.

Rabin, M. (1993). "Incorporating Fairness into Game Theory and Economics". American Economic Review, 83(5), 1281-1302.

Rabin, M. (1998). "Psychology and Economics". Journal of Economic Literature, 36(1), 11-46.

Rey Biel, P. (2008) "Inequity Aversion and Team Incentives". Scandinavian Journal of Economics, 110(2), 297-320.

Rob, R. and Zemsky, P. (2002). "Social Capital, Corporate Culture, and Incentive Intensity". RAND Journal of Economics, 33(2), 243-257.

von Siemens, F. (2011). "Heterogeneous Social Preferences, Screening, and Employment Contracts". Oxford Economic Papers, 63(3), 499-522.

von Siemens, F. (2012). "Social Preferences, Sorting, and Competition". Scandinavian Journal of Economics, 114(3), 780-807.

Smith, R.H., Webster, J.M., Parrott, W.G. and Eyre, H.L. (2002). "The Role of Public Exposure in Moral and Nonmoral Shame and Guilt". Journal of Personality and Social Psychology, 83(1), 138-159.

Sugden, R. (1984). "Reciprocity: The Supply of Public Goods Through Voluntary Contributions". Economic Journal, 94(376), 772-787.

Young, H.P. (1998). "Social Norms and Economic Welfare". European Economic Review, 42(3-5), 821-830.

Ziv, A. (1993). "Performance Measures and Optimal Organization". Journal of Law, Economics, and Organization, 9(1): 30-50.

Ziv, A. (2000). "Information Technology and Optimal Firm Structure". Journal of Accounting Research, $38(2), 297-328$. 